\title{
Identifying Amygdala-Like Territories in Scyliorhinus canicula (Chondrichthyan): Evidence for a Pallial Amygdala
}

\author{
Isabel Rodríguez-Moldes ${ }^{a}$ Idoia Quintana-Urzainqui ${ }^{a}$ b \\ Gabriel Nicolás Santos-Durán ${ }^{a, c}$ Susana Ferreiro-Galve ${ }^{a}$ \\ Santiago Pereira-Guldrís ${ }^{\mathrm{a}}$ María Candás ${ }^{d}$ Sylvie Mazan ${ }^{\mathrm{e}}$ Eva Candal ${ }^{\mathrm{a}}$ \\ ${ }^{a}$ Grupo Neurodevo, Departamento de Bioloxía Funcional, Centro de Investigación en Bioloxía (CIBUS), Universidade

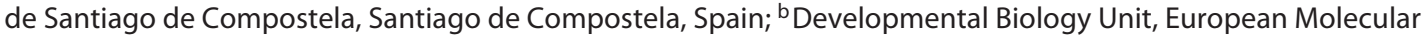 \\ Biology Laboratory (EMBL), Heidelberg, Germany; ${ }^{C}$ Laboratory of Artificial and Natural Evolution (LANE), \\ Department of Genetics and Evolution, University of Geneva, Geneva, Switzerland; ${ }^{d}$ REBUSC-Marine Biology Station

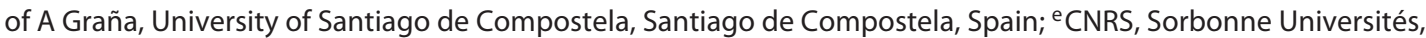 \\ UPMC Univ Paris 06, UMR7232, Observatoire Océanologique, Banyuls, France
}

\section{Keywords}

Elasmobranchs · Sharks · Telencephalon · Pallium •

Development · Evolution

\begin{abstract}
To identify the putative amygdalar complex in cartilaginous fishes, our first step was to obtain evidence that supports the existence of a pallial amygdala in the catshark Scyliorhinus canicula, at present the prevailing chondrichthyan model in comparative neurobiology and developmental biology. To this end, we analyzed the organization of the lateral walls of the telencephalic hemispheres of adults, juveniles, and early prehatching embryos by immunohistochemistry against tyrosine hydroxylase $(\mathrm{TH})$, somatostatin (SOM), Pax6, serotonin (5HT), substance $P(S P)$, and Met-enkephalin (MetEnk), calbindin-28k (CB), and calretinin (CR), and by in situ hybridization against regulatory genes such as Tbr1, Lhx9, Emx1, and $D / x 2$. Our data were integrated with those available from
\end{abstract}

karger@karger.com www.karger.com/bbe

Karger $\stackrel{\text { ' }}{5}$

BOPEN ACCESS
(C) 2021 The Author(s)

Published by S. Karger AG, Basel

This is an Open Access article licensed under the Creative Commons Attribution-NonCommercial-4.0 International License (CC BY-NC) (http://www.karger.com/Services/OpenAccessLicense), applicable to the online version of the article only. Usage and distribution for commercial purposes requires written permission. the literature related to the secondary olfactory projections in this shark species. We have characterized two possible amygdalar territories. One, which may represent a ventropallial component, was identified by its chemical signature (moderate density of Pax6-ir cells, scarce TH-ir and SOM-ir cells, and absence of CR-ir and CB-ir cells) and gene expressions (Tbr1 and Lhx9 expressions in an Emx 1 negative domain, as the ventral pallium of amniotes). It is perhaps comparable to the lateral amygdala of amphibians and the pallial amygdala of teleosts. The second was a territory related to the pallial-subpallial boundary with abundant Pax6-ir and CR-ir cells, and 5HT-ir, SP-ir, and MetEnk-ir fibers capping dorsally the area superficialis basalis. This olfactory-related region at the neighborhood of the pallial-subpallial boundary may represent a subpallial amygdala subdivision that possibly contains migrated cells of ventropallial origin.

(C) 2021 The Author(s)

Published by S. Karger AG, Basel
Correspondence to:

Isabel Rodríguez-Moldes, isabel.rodriguez-moldes@usc.es 


\begin{tabular}{ll}
\hline Abbreviations used in this paper \\
\hline ABB & alar-basal boundary \\
AC & anterior commissure \\
asb & area superficialis basalis \\
cer & cerebellum \\
Di & diencephalon \\
DP & dorsal pallium \\
DPc & caudal part of the dorsal pallium \\
h & habenula \\
HL & hypothalamic lobus \\
Hy & hypothalamus \\
IHB & intrahypothalamic border \\
LNI & neurointermediate lobe of the hypophysis \\
LP & lateral pallium \\
MP & medial pallium \\
OB & olfactory bulb \\
OC & optic chiasm \\
OO & olfactory organ \\
On & optic nerve \\
OT & optic tectum \\
POA & preoptic region \\
PPa & peduncular paraventricular region \\
PSB & presumptive pallial subpallial boundary \\
PThE & prethalamic eminence \\
Rh & rhombencephalon \\
Sp & subpallium \\
S-str & striatum of Smeets \\
TEL & telencephalon \\
VP & ventral pallium \\
VP* & \\
\hline &
\end{tabular}

\section{Introduction}

The amygdala or amygdalar complex is an evolutionarily conserved structure formed by a group of nuclei in the caudoventrolateral telencephalon, which is of heterogeneous embryological origin (it is held to originate in different pallial and subpallial sectors), and constitutes a functional system that controls behavior and physiology, and shows some common traits among tetrapods [Swanson and Petrovich, 1998]. Studies in mouse embryos based on the patterns of expression of developmental regulatory genes of Emx, Dlx, Tbr1, Nkx, and Pax families used as markers of developmental forebrain subdivisions, revealed that the molecular and structural heterogeneity of the mammalian amygdala is based on the pallial or subpallial origin of its nuclei, with the different amygdalar subdivisions containing derivatives of the lateral pallium, the ventral pallium, and of subpallial structures as the striatum, and the pallidum [Fernández et al., 1998; Puelles et al., 1999, 2000]. Studies of Luis Puelles and collaborators have contributed to identify and characterize the pallial and subpallial subdivisions of the amygdala in mouse and other tetrapods [Puelles et al., 2000, 2016; Brox et al., 2002; Bardet et al., 2006; García-López et al., 2008]. In recent years he has departed from his earlier views in favor of a radial concept of the pallial amygdalar subdivisions in a pattern strictly separate from the cortical pallium sectors [Garcia-Calero et al., 2020, 2021; Garcia-Calero and Puelles, 2020, 2021]. The amygdala of mammals, reptiles, birds, and amphibians has been analyzed in relevant comparative revisions [Martínez-García et al., 2002, 2006; Moreno and González, 2006; 2007a; Medina et al., 2011, 2017]. Such comparative studies have revealed a common structural organization, along with shared functional roles (revised in Pabba [2013]). Several key features of the organization of this complex have been shown to be shared by tetrapods and to be present in their common ancestor, as shown by comparative studies in lungfishes, the closest living relatives of tetrapods [Moreno et al., 2018). These features are related to its double origin (formed by pallial and subpallial derivatives), topography (at the caudoventrolateral part of the telencephalic hemisphere), and connections (strongly related to the olfactory and vomeronasal systems, and the origin of important hypothalamic projections) [Moreno and González, 2006, 2007a]. These studies suggest that the ancestral condition of the amygdala in the common ancestor of tetrapods would consist in a cortical (pallial) amygdala that receives chemosensory information (mainly olfactory) and a subpallial amygdala (composed of medial and central extended amygdala), which together with the striatum would mediate unconditioned emotional behavioral responses. In this scenario, two new acquisitions would characterize the amygdala of amniotes which allow them to process stimuli prior to their emotional evaluation: the basolateral amygdala (a deep part of the pallial amygdala) and the superficial cortical amygdala [Martínez-García et al., 2006]. This evolutionary interpretation has been related to the spatial arrangement of the amygdalar nuclei in mammals, with the more conserved central and medial nuclei occupying the most medial position followed by the basolateral complex and by the emergent cortical amygdalar nuclei, which occupy the most lateral position [Moreno and González, 2006]. Studies in amphibians and sarcopterygian fishes performed during decades by the group of Agustín González have been crucial to underpin this evolutionary view about the amygdalar complex and, in general, to decipher telencephalic evolution across the anamniote-amniote transition. Their studies have provided very detailed information about the chemoarchitecture, gene expression pat- 
terns, and connections of the telencephalon of anuran, urodele, and gymnophionan amphibians [Marín et al., 1998; Moreno and González, 2003, 2004, 2005, 2006, 2007a, b, c; Moreno et al., 2005; 2014; López et al., 2007; Morona and González, 2008; Joven et al., 2013a, b, c; González et al., 2017]. Three amygdalar subdivisions have been identified and characterized in this tetrapod anamniote group that may represent an ancestral amygdalar condition: the lateral amygdala (LA), associated to the ventral pallium, which receives secondary olfactory fibers; the medial amygdala, which represents the subpallial vomeronasal component; and the likewise subpallial central amygdala, mainly related to autonomic functions [Moreno and González, 2006].

Comparisons among tetrapods and non-tetrapods (fishes) are crucial to investigate the origin and degree of evolutionary conservation of a primordial amygdala field but studies with this approach are scarce [Moreno and González, 2007a; Medina et al., 2011, 2017; Porter and Mueller, 2020; Gerlach and Wullimann, 2021] and are mainly focused on actinopterygians (ray-finned fishes). In this fish group the telencephalon develops by eversion, a morphogenetic process that reverses the topology of telencephalic structures with respect to that in other gnathostome fishes. In lobe-finned fishes (sarcopterygian fishes) and chondrichthyans (cartilaginous fishes), the telencephalon develops by evagination, as in tetrapods, which involves an outward expansion of the pial surface of the telencephalic walls (revised in Nieuwenhuys and Puelles [2016]).

Comparative studies including the amygdala of fishes were also provided by the group of Agustín González and R. Glen Northcutt delving on the amygdalar organization in sarcopterygian fishes [González and Northcutt, 2009, 2011; Northcutt, 2009; González et al., 2010; Northcutt and González, 2011; López et al., 2017]. In lobe-finned fishes such as the lungfish, an amygdaloid complex with at least three components, lateral, medial, and central nuclei, that correspond directly to similarly named amygdaloid subdivisions in amphibians, was recognized based on neurochemical, genoarchitectonic, and hodological data [González and Northcutt, 2009; Northcutt, 2009; González et al., 2010; Lópezet al., 2017]. Moreover, Agustín González and R. Glen Northcutt studied the organization of the telencephalon in another relevant sarcopterygian species, the coelacanth Latimeria chalumnae, due to its evolutionary implications, where these authors have recognized amygdalar nuclei based on their similarity with the identically named structures described in lungfishes [González and Northcutt, 2011; Northcutt and González, 2011].

The Catshark Pallial Amygdala
Despite the added difficulty to identify the homologies of the telencephalic pallial sectors in actinopterygians because of the eversion process, various pallial and subpallial subdivisions and candidates to the different amygdalar-like nuclei have been proposed, considering not only the topography but also topological, genetic, functional, neuroanatomical, and developmental approaches [Perathoner et al., 2016; Biechl et al., 2017; Porter and Mueller, 2020; Gerlach and Wullimann, 2021]. In actinopterygians there is agreement recognizing that the medial part of the pallium (Dm) includes the homolog of the pallial amygdala of terrestrial vertebrates and has a ventral pallial molecular profile [Bradford, 1995, 2009; Northcutt, 2011; Mueller et al., 2011; Maximino et al., 2013; von Trotha et al., 2014; Lal et al., 2018; Porter and Mueller, 2020; Gerlach and Wullimann, 2021]. However, the descriptions of the extent of amygdala-homolog territories vary among the different authors.

Chondrichthyans represent an ancient radiation of gnathostomes whose phylogenetic position is that of an out-group to all other living jawed vertebrates. Therefore it becomes crucial to gain knowledge about the telencephalon evolution during the agnathan-gnathostome transition. Despite its theoretical relevance in comparative studies, literature about the possible amygdalar territories in cartilaginous fishes is notably scarce. As far as we know, only the works of Williams [1973] and Northcutt et al. [1988], both referring to the squalomorph Squalus acanthias, have tried to identify amygdalar components in chondrichthyans. Williams described the amygdala of newborn Squalus as formed by three pallial components, the anterior, corticomedial, and basolateral amygdaloid divisions, named following Schnitzlein et al. [1967]. In the adult Squalus, Northcutt et al. [1988] identified a nucleus that they called nucleus A as the homolog of the pallial amygdala of land vertebrates. None of the reference works about chondrichthyans like those of Smeets et al. [1983] and Smeets [1998] mentioned possible amygdalar territories in the four species studied, which included Scyliorhinus. The first reference to a possible amygdalar territory in this species appeared in a developmental study [Quintana-Urzainqui et al., 2012] referring to a region that contained a conspicuous density of Pax6-immunoreactive cells on top of the area superficialis basalis (a subpallial structure).

Distinct subdivisions of the amygdalar complex have been characterized in mouse by means of extensive developmental studies analyzing the expression of several regulatory genes [Medina et al., 2004; Legaz et al., 2005; among others] in conventional coronal (transverse), sag-

Brain Behav Evol 2021;96:283-304 
ittal, and horizontal sections. The importance of ad hoc section planes has been recently pointed out by Luis $\mathrm{Pu}$ elles and his colleagues [Garcia-Calero and Puelles, 2020] to allow visualizing whole (or nearly so) radial domains in the amygdalar region. This ad hoc methodological approach has allowed them to build a model of amygdalar histogenesis based on the radial glial organization of the pallium [Garcia-Calero et al., 2020; Garcia-Calero and Puelles, 2020]. Moreover, the cortical ring model of $\mathrm{Pu}-$ elles et al. [2019] proposes a topological overall modeling of cortical pattern based on a double-ring organization of the pallium, which considers the pallial amygdala as an independent complex structure located outside the outer cortical ring, that is, topologically external to the cortical pallium. Based on these two models, Luis Puelles and his colleagues have recently reformulated the amygdalar organization of mammals [Puelles et al., 2019; Garcia-Calero et al., 2020; Garcia-Calero and Puelles, 2020]. This new paradigm to compare the amygdalar organization among vertebrates will need to be tested in the different model species before it may be recognized as being as useful for comparative neuroanatomists as has been the updated prosomeric model of Puelles and Rubenstein [2015].

In an attempt to identify the putative amygdalar complex in cartilaginous fishes, our first step was to put together cytological, neurochemical, and genoarchitectonic evidence obtained from conventional transverse sections that may support the existence of a pallial amygdala in the catshark Scyliorhinus canicula, at present the prevailing chondrichthyan model in comparative neurobiology and developmental biology. We have analyzed the cytoarchitecture and chemoarchitecture of the lateral walls of the caudal telencephalic hemispheres of adults, juveniles, and prehatching embryos to recognize territories and structures defined by their chemical nature. Immunoreactivities to tyrosine hydroxylase (TH), somatostatin (SOM), Pax6, serotonin (5HT), substance P (SP), and Met-enkephalin (MetEnk) were selected as known markers of the catshark pallial (TH, SOM, Pax6) and subpallial (5HT, $\mathrm{SP}$, MetEnk) regions. In addition, the differential distribution of immunoreactivity for calbindin-28k (CB) and calretinin (CR) was also studied. The analysis of the distribution of these markers in adults, juveniles, and stage-32 (S32) embryos, helped us to correlate the adult territories with corresponding embryonic domains. We also analyzed comparatively the differential expression of several developmental regulatory genes (Tbr1, Lhx9, $E m x 1$, and $D l \times 2$ ) in prehatching embryos to identify the histogenetic divisions of the pallium and to correlate them with the cyto- and chemoarchitecture from pre- hatching stages to adulthood. Our data were integrated with those available from the literature related to the secondary olfactory projections in this shark species [Smeets, 1983; Yáñez et al., 2011]. The study of the subpallial amygdalar component deserves a more detailed analysis that exceeds the extent of the present work and will be considered in a separate work.

\section{Materials and Methods}

\section{Experimental Animals and Tissue Preparation}

Male and female adults (45-60 cm in length), juveniles (9-12 $\mathrm{cm}$ in length), and embryos at stage 32 [Ballard et al., 1993] of the catshark Scyliorhinus canicula L. were used in this study. This embryonic stage marks the beginning of the prehatching period according to Ballard et al. [1993], which represents half of all development time. This developmental period can be roughly recognized in other vertebrates, although the time of occurrence varies largely because of sizeable differences in the length of the embryonic period (see Rodríguez-Moldes et al. [2011, 2017] for proposed correspondences to embryonic stages of different vertebrate models as mouse, chick, and zebrafish). For more information about the relationship of the catshark embryonic stage with body size, incubation, and birth see Pose-Méndez et al. [2016].

Animals were supplied by local fishermen (adults), the Marine Biological Model Supply Service of the CNRS UPMC Roscoff Biological Station (France), and Aquaria of O Grove (Pontevedra, Spain) and Finisterrae (A Coruña, Spain). Adequate measures were taken to minimize animal pain or discomfort. The original research reported herein was performed according to the regulations and laws established by the European Union (2010/63/UE) and by the Spanish Royal Decree 1386/2018 for the care and handling of animals in research and were approved by the Ethics Committee of the University of Santiago de Compostela. Animals were deeply anesthetized with $0.5 \%$ MS-222 in seawater previously to any experimental procedure.

Adults and juveniles were intracardially perfused with elasmobranch Ringer's solution followed by $4 \%$ paraformaldehyde in elasmobranch's phosphate buffer (containing urea). The brains were then dissected out and immersed in the same fixative for $4 \mathrm{~h}$. Embryos were fixed by immersion in paraformaldehyde for $72 \mathrm{~h}$. After rinsing in phosphate buffered (PB) saline, brains and embryos were cryoprotected with $30 \%$ sucrose in $\mathrm{PB}$, embedded in OCT compound (Tissue Tek, Torrance, CA, USA), and frozen with liquid-nitrogen-cooled isopentane. Parallel series of sections (12-20 $\mu \mathrm{m}$ thick) were cut in transverse planes in relation to the longitudinal body axis on a cryostat and mounted on Superfrost Plus (Menzel-Glasser, Madison, WI, USA) slides. For more details about the procedure, see Carrera et al. [2012]. Sections of adult and juvenile telencephala stained with hematoxylin-eosin or with cresyl violet were used for general cytoarchitectonic analysis.

\section{Immunohistochemistry}

As primary antisera we used polyclonal rabbit anti-5HT (DiaSorin/Immunostar; 1:2,500-5,000), anti-SP (ICN Biomedicals; 1:1,000-2,000), anti-MetEnk (Affiniti, Exeter, UK; dilution 1:1,000), anti-SOM-14 (Chemicon; 1:500), anti-CB (Swant; 1:800), 
anti-Pax6 (Covance; 1:400), anti-CR (Swant; 1:250-500), and monoclonal mouse anti-TH (Milipore/Chemicon; 1:500-1,000).

Details of the procedures and the specificity of the antibodies used have been published elsewhere [Rodríguez-Moldes et al., 1993; Anadón et al., 1995; Carrera et al., 2008, 2012; Rodríguez Díaz et al., 2011; Ferreiro-Galve et al., 2012; Quintana-Urzainqui et al., 2014; Sánchez-Farías and Candal, 2015; Pose-Méndez et al., 2016, 2017]. Briefly, sections were pre-treated with $0.01 \mathrm{M}$ citrate buffer ( $\mathrm{pH}$ 6.0) for $30 \mathrm{~min}$ at $95^{\circ} \mathrm{C}$ for heat-induced epitope retrieval, rinsed in $0.05 \mathrm{M}$ Tris-buffered saline (TBS; pH 7.4), and incubated overnight with the primary antibody in a humid chamber at room temperature overnight. After rinsing in TBS, appropriate secondary antibodies (horseradish peroxidase-conjugated goat anti-rabbit and anti-mouse, Biorad, diluted 1:200) were incubated for $1 \mathrm{~h}$ at room temperature. After rinsing with TBS, the immunolabeling was visualized with $0.25 \mathrm{mg} / \mathrm{mL}$ diaminobenzidine tetrahydrochloride (DAB; Sigma) in TBS with $0.00075 \% \mathrm{H}_{2} \mathrm{O}_{2}$ and $2.5 \mathrm{mg} / \mathrm{mL}$ nickel ammonium sulfate (blue precipitate) or with SIGMAFAST ${ }^{\mathrm{TM}}$ 3,30-DAB tablets (Sigma; brown precipitate). All dilutions were made with TBS containing $2 \%$ bovine serum albumin (Sigma), 15\% normal goat serum (Dako) or normal donkey serum (Dako), and $0.2 \%$ Triton X-100 (Sigma). Finally, the sections were dehydrated, mounted, and coverslipped.

Some series of sections of S32 embryos were treated for double immunofluorescence with cocktails at optimal dilutions of primary antibodies against CR (polyclonal rabbit, Swant) or Pax6 (polyclonal rabbit, Covance), plus DCX (polyclonal goat, Santa Cruz Biotechnology) and GAD (polyclonal sheep; from I. Kopin and W. Oertel), and subsequently detected using mixtures of appropriate Alexa Fluor-conjugated secondary antibodies (donkey anti-sheep 488 , donkey anti-rabbit 546, and donkey anti-goat 633). Sections were rinsed in distilled water, allowed to dry, and mounted in Mowiol 4-88 Reagent (Calbiochem). For more details about the source and specificity of such primary antibodies, see QuintanaUrzainqui et al. [2014] (goat anti-DCX) and Pose-Méndez et al. [2016] (sheep anti-GAD and Alexa Fluor-conjugated secondary antibodies).

\section{In situ Hybridization on Sections}

Sense and antisense digoxigenin-UTP-labeled Tbr1, Lhx9, Emx1, and Dlx2 (ScTbr1, ScLhx9, ScEmx1, and ScDlx2) were synthesized directly by transcription in vitro. In situ hybridization was performed on cryostat sections of embryos at stage 32 following standard protocols [Coolen et al., 2007]. For information about the origin of the probes see Quintana-Urzainqui et al. [2015] and Santos-Durán et al. [2015, 2016]. These probes were selected from a $S$. canicula embryonic cDNA library, constructed in PSPORT1, and submitted to high-throughput EST sequencing. Selected cDNA fragments were cloned in pSPORT vectors. Sense and antisense digoxigenin-UTP-labeled and fluorescein-UTP-labeled probes were synthesized directly by in vitro transcription using as templates linearized recombinant plasmid DNA or cDNA fragments prepared by PCR amplification of the recombinant plasmids. Briefly, sections were permeabilized with proteinase $\mathrm{K}$, hybridized with sense or antisense probes overnight at $65^{\circ} \mathrm{C}$, and incubated with the alkaline phosphatase-coupled anti-digoxigenin and antifluorescein antibody (1:2,000, Roche Applied Science, Manheim, Germany) overnight at $4{ }^{\circ} \mathrm{C}$. The color reaction was performed in the presence of BM-Purple (Roche). Control sense probes did not produce any detectable signal.

The Catshark Pallial Amygdala

\section{Image Acquisition}

Bright field images were obtained with an Olympus BX51 and AX70 photomicroscopes equipped with an Olympus DP71 and DP70 color digital camera, respectively. Fluorescent double-labeled sections were photographed with a spectral confocal laser scanning microscope.

\section{Micro-CT Imaging}

One adult brain and one S32 embryo were removed from fixative by washing several times with PB saline for 2 days, dehydrated in increasing concentrations of methanol, and stained with $1 \%$ phosphotungstic acid in methanol for 4 days before micro-CT scanning with a Bruker Skyscan 1172 microtomograph (Bruker, Kontich, Belgium) located at the Marine Biology Station of the University of Santiago de Compostela in A Graña. The obtained images were digitally reconstructed with NRecon software (Bruker, Kontich, Belgium) and processed with CTAnalyzer software (Bruker, Kontich, Belgium). For displaying data, DataViewer software (Bruker, Kontich, Belgium) was used. Serial images of the three axis and $3 \mathrm{D}$ reconstructed images of each sample were obtained.

\section{Results}

Our hypothesis was that parts of an amygdalar complex with characteristics similar to those of tetrapods in principle should be recognized in chondrichthyans. Having taken into account the topologic relative position of the amygdala in tetrapods within the pallial Bauplan, external to the cortical pallium [Puelles et al., 2019], we localized the amygdala candidate region in the catshark in a lateral region within the telencephalic hemisphere that overlies the subpallium, underlies the olfactory pallial territories (those adjacent to the olfactory bulbs), and is externally located in relation to the medial pallium.

We searched for such evidence through the analysis of the cyto-, chemo-, and genoarchitecture organization of the lateral telencephalic walls of prehatching embryos, juveniles, and adults of the catshark. We recognized characteristics compatible with the existence of a pallial amygdala in a region comprised between the lateral pallium and the area superficialis basalis from levels caudal (topologically ventral) to the olfactory bulb (Fig. 1a) to the level of the anterior commissure (Fig. 1b). In adults of S. canicula, this territory corresponds to the pallial territory where secondary olfactory fibers terminate, as demonstrated by Smeets [1983] with degeneration experiments, but appeared unnamed in the reference atlas of Smeets et al. [1983], where it is only mentioned in relation to the course of secondary olfactory fibers. Based on the images provided in the atlas by Smeets et al. [1983], we 

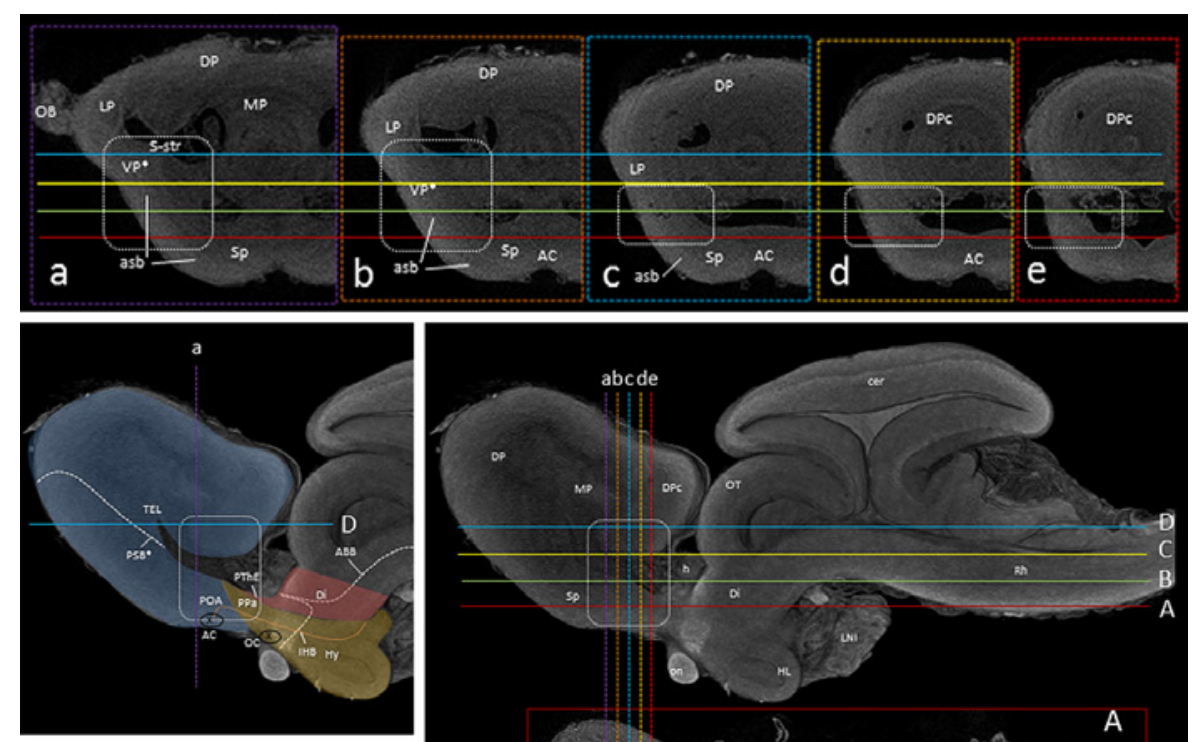

Fig. 1. Micro-CT imaging of the adult brain of Scyliorhinus canicula showing individual sections from the $3 \mathrm{D}$ reconstruction. Lines a-e indicate the level of the transverse sections from rostral to caudal telencephalic levels (a-e) and lines A-D indicate the level of the horizontal sections from ventral to dorsal. The confluence of both section planes is indicated with a squared area in the sagittal 3D reconstruction (up in the column of images) and corresponds to the telencephalic territory where we search for the presumptive pallial amygdala. At the left, such area is related to the estimated extension of the hypothalamo-telencephalic structural unit (secondary prosencephalon) and the diencephalon. The foreseeable alar-basal boundary (ABB) and the pallial-subpallial boundary (PSB) are represented. Scale bar, $1 \mathrm{~mm}$. For abbreviations, see list.

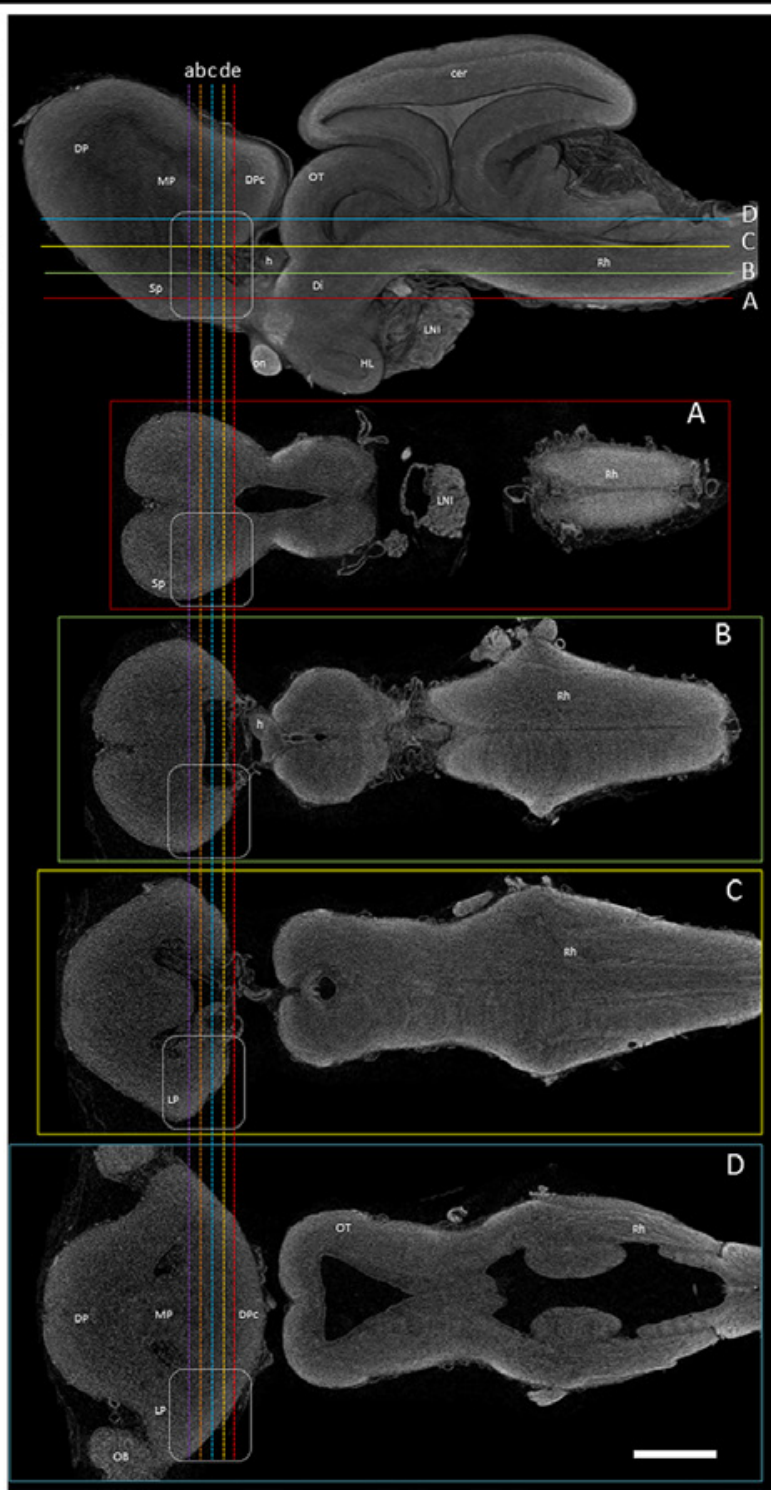

define the region analyzed here as the territory dorsal to the area superficialis basalis and ventral to the olfactory bulb insertion, the retrobulbar area, and the lateral pallium. Tentatively we label it as the possible pallial subdivision of the catshark amygdalar complex. According to the updated prosomeric model [Puelles and Rubenstein, 2015], this area is topologically situated just dorsal to the hypothalamic-telencephalic transition (see Fig. 1, left) and includes derivatives of histogenetic domains of the ventral-most pallium (ventral pallium and lateral pallium), the ventral-most subpallium (preoptic area and medial and lateral ganglionic eminences-like), the dorsalmost hypothalamus (peduncular paraventricular area), and the rostral-dorsal-most diencephalon (prethalamic 

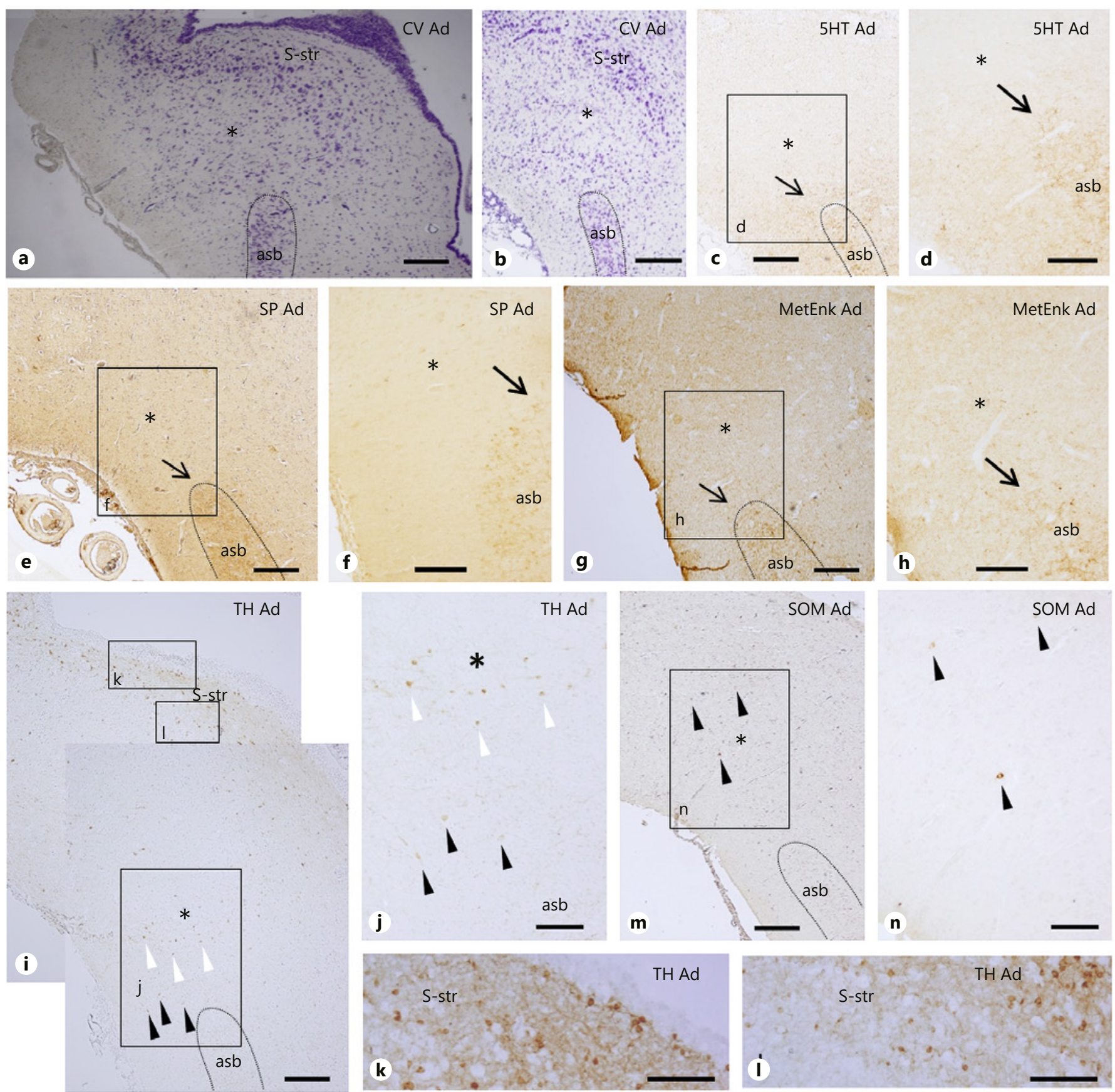

Fig. 2. Transverse sections of the adult (Ad) telencephalon of the catshark stained with cresyl violet (CV) and immunohistochemistry to serotonin (5HT), substance P (SP), Met-enkephalin (MetEnk), tyrosine hydroxylase (TH), and somatostatin (SOM). The asterisk indicates the pallial amygdala prospective region. Arrows

in $\mathbf{c - h}$ indicate an area capping the area superficialis basalis (asb). Black arrowheads in $\mathbf{i}, \mathbf{j}, \mathbf{m}$, and $\mathbf{n}$ point to immunoreactive cells. White arrowheads in $\mathbf{i}$ and $\mathbf{j}$ point to some of the radially disposed cells from the TH-ir cell population. Scale bar, $500 \mu \mathrm{m}(\mathbf{a}-\mathbf{i}, \mathbf{m})$, $200 \mu \mathrm{m}(\mathbf{j}, \mathbf{k}, \mathbf{I}, \mathbf{n})$. For more abbreviations, see list.

eminence). For the extension and molecular profile of these domains in catshark, see Quintana-Urzainqui et al. [2012, 2015], Santos-Durán et al. [2015, 2016], and Rodríguez-Moldes et al. [2017].
We used micro-CT imaging to study the gross topography of the telencephalon and delimit the extent of the amygdalar territory studied in adult brains (Fig. 1). This technique provides sagittal, transverse, and horizontal 


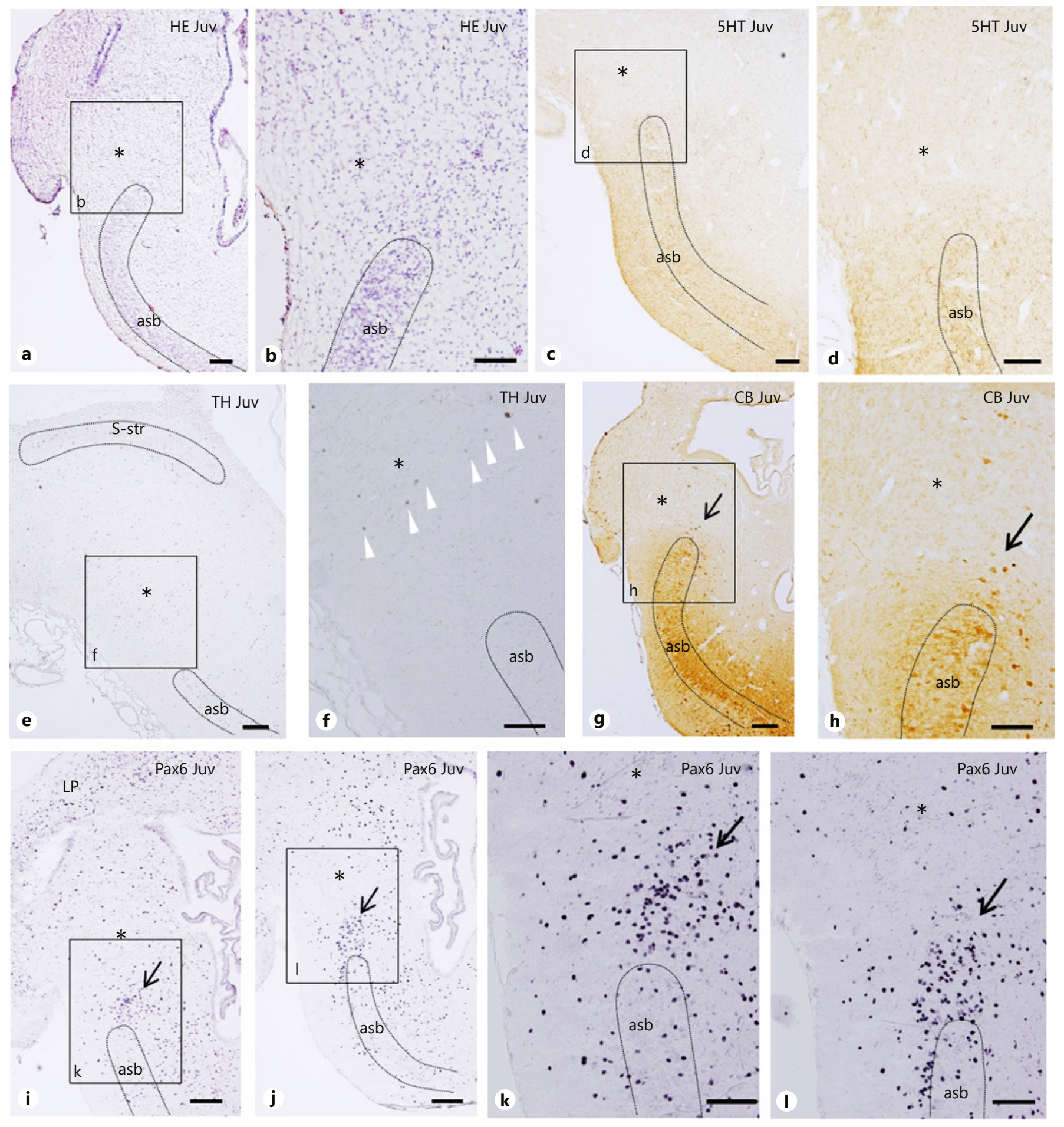

Fig. 3. Transverse sections of the juveniles (Juv) telencephalon of the catshark stained with hematoxylin-eosin (HE) and immunohistochemistry to serotonin (5HT), tyrosine hydroxylase (TH), calbindin (CB), and Pax6. The asterisk indicates the pallial amygdala prospective region. White arrowheads in $\mathbf{f}$ point to radially disposed TH-ir cells. Arrows in $\mathbf{g}-\mathbf{I}$ point to the population of cells immunoreactive to $\mathrm{CB}(\mathbf{g}, \mathbf{h})$ and to Pax6 (i-I) that are capping the area superficialis basalis (asb). Scale bar, $500 \mu \mathrm{m}(\mathbf{a}, \mathbf{c}, \mathbf{e}, \mathbf{g}, \mathbf{i}, \mathbf{j}), 200$ $\mu \mathrm{m}(\mathbf{b}, \mathbf{d}, \mathbf{f}, \mathbf{h}, \mathbf{k}, \mathbf{I})$. For more abbreviations, see list. 
Fig. 4. Micro-CT imaging of the head of a stage-32 embryo of Scyliorhinus canicula showing individual sections from the $3 \mathrm{D}$ reconstruction. The level of the sagittal $(\mathbf{A}$, $\left.\mathbf{A}^{\prime}\right)$ and transverse sections $(\mathbf{a}, \mathbf{b})$ are indicated in the horizontal section (B). The confluence of both section planes is indicated with a squared area in the horizontal section (B) and corresponds to the telencephalic territory where we search for the presumptive pallial amygdala. Scale bar, 1 mm. For abbreviations, see list.

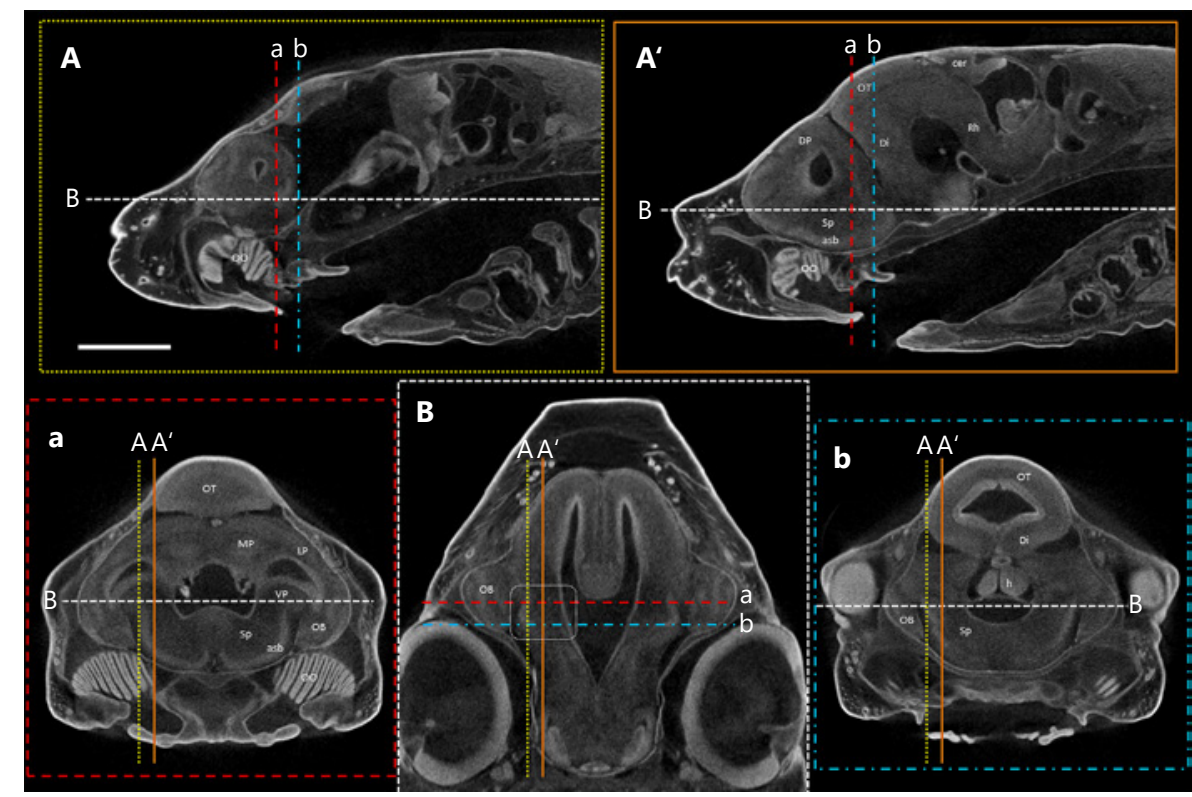

sections of a single sample, thus facilitating three-dimensional visualization of telencephalic topography. We selected single micro-CT sections of an adult brain cut in transverse (Fig. 1a-e) and horizontal (Fig. 1A-D) planes through the region of interest. Such sections allow recognizing the main anatomical landmarks and also help to identify the levels of equivalent transverse histological sections shown in Figures 2 (adults) and 3 (juveniles). The relative position of the telencephalic structures will be described in relation to the anterior-posterior, dorso-ventral, and medio-lateral axes defined according to the apparent straight longitudinal head axis (not to the bent prosomeric forebrain axis).

Cresyl violet-stained adult sections reveal that the pallial amygdala candidate presents a cytoarchitecture distinctive from the adjacent territories. While the area superficialis basalis (asb in Fig. 2a, b) and Smeets' "striatum" (S-str in Fig. 2a, b) are densely packed nuclear groups, the cell density in the supposed pallial amygdala territory is lower and its cells are sparsely distributed (asterisks in Fig. 2a, b). Immunohistochemistry also reveals neurochemical differences among these regions. Immunoreactivities to 5HT, SP, and MetEnk are absent in the proposed pallial amygdala territory (asterisks in Fig. 2ch) while a moderate density of 5HT-, SP-, and MetEnkimmunoreactive (ir) fibers (arrows in Fig. 2c-h) innervate the region just bordering the dorsolateral pole of the area superficialis basalis (asb in Fig. 2c-h). This subpallial territory is clearly distinguished by its densely packed cells and the dense innervation by fibers and their terminal fields immunoreactive to 5HT (only fibers), SP, and MetEnk, as it has been described in previous works [Rodríguez-Moldes et al., 1993; Carrera et al., 2008; Quintana-Urzainqui et al., 2012], which contrasts with the absence of these immunomarkers in the adjacent pallium. These differences evidence a kind of boundary or interface that roughly could correspond to the lateral extent of the pallial-subpallial boundary, which will be used as a reference for the ventral extent of the pallial amygdalalike territory. Remarkably, in the presumed pallial amygdala there are scattered $\mathrm{TH}$-ir cells, most of them forming a radially oriented nuclear group (white arrowheads in Fig. 2i, j). The scarcity of TH-ir cells in the presumed pallial amygdala contrasts with the abundance of TH-ir cells and fibers in the periventricular band that corresponds to the striatum of Smeets (S-str in Fig. 2i, k, l). These periventricular walls show a moderate density of SOM-ir cells. SOM-ir cells are also observed, although less abundantly in the presumed pallial amygdalar territory (Fig. 2m, n).

Cytoarchitectonic analysis in juveniles using classical staining reveals that, although the cell density throughout the telencephalon is rather homogeneous, differences among territories can be noted, which is evident in the lower cell density in the pallial territory dorsal to the area superficialis basalis (asterisk in Fig. 3a, b). The region we propose as pallial amygdala territory in juveniles showed labelled olfactory fibers traced from the olfactory bulb 

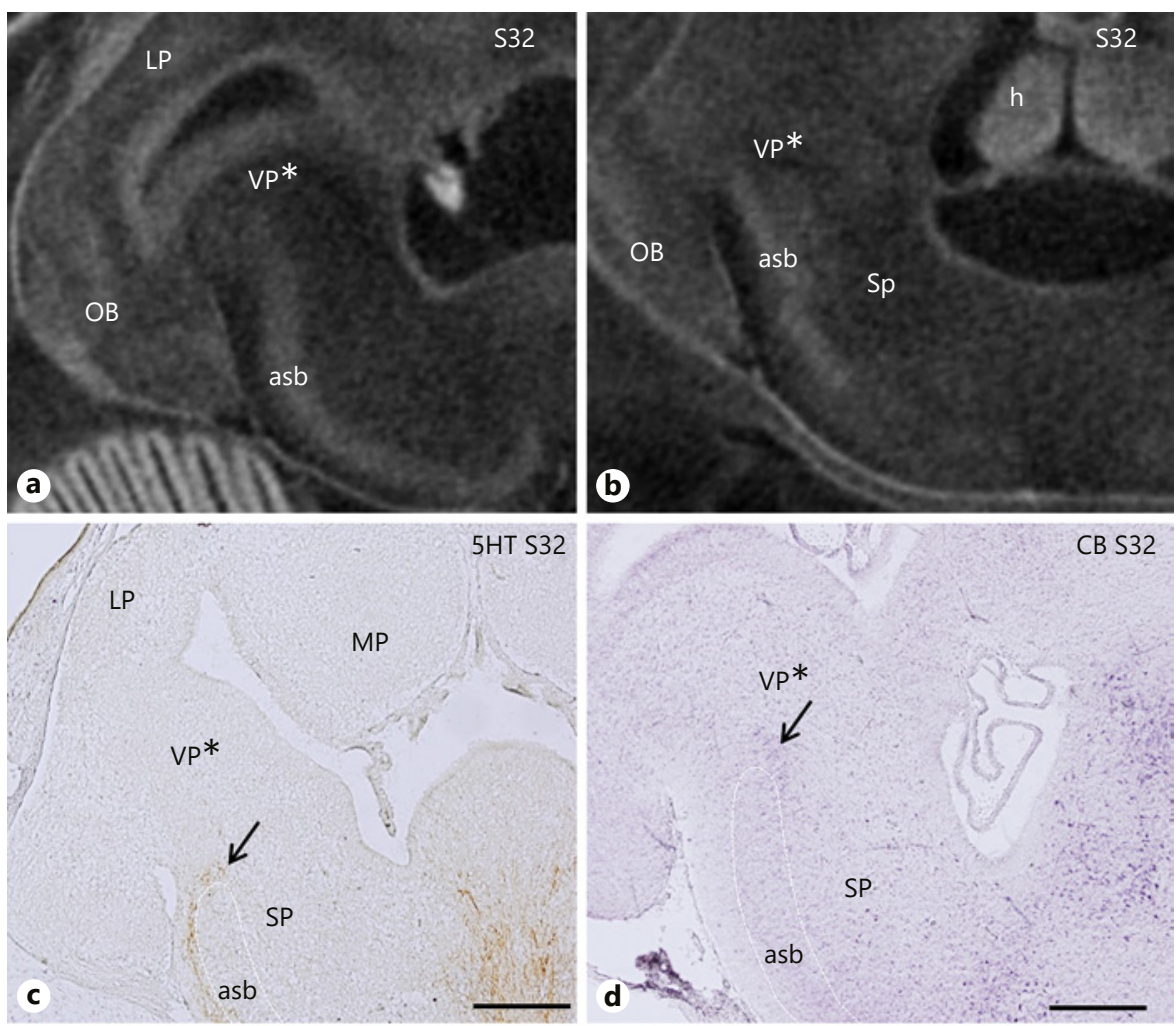

Fig. 5. Transverse sections through the telencephalon of stage-32 embryos (S32) of the catshark. $\mathbf{a}$ and $\mathbf{b}$ are details of Figure 4 to use as references of the levels of histological sections showing immunoreactivity to serotonin $(5 \mathrm{HT})$, calbindin $(\mathrm{CB})$, calretinin (CR), and Pax6. The prospective pallial amygdala is indicated as $\mathrm{VP}^{*}$. Arrows in c-f point to $5 \mathrm{HT}$-ir fibers (c) and to CB-ir (d), CR-ir (e), and Pax6-ir (f) cells that are capping the area superficialis basalis (asb). Scale bar, $500 \mu \mathrm{m}$. For more abbreviations, see list.
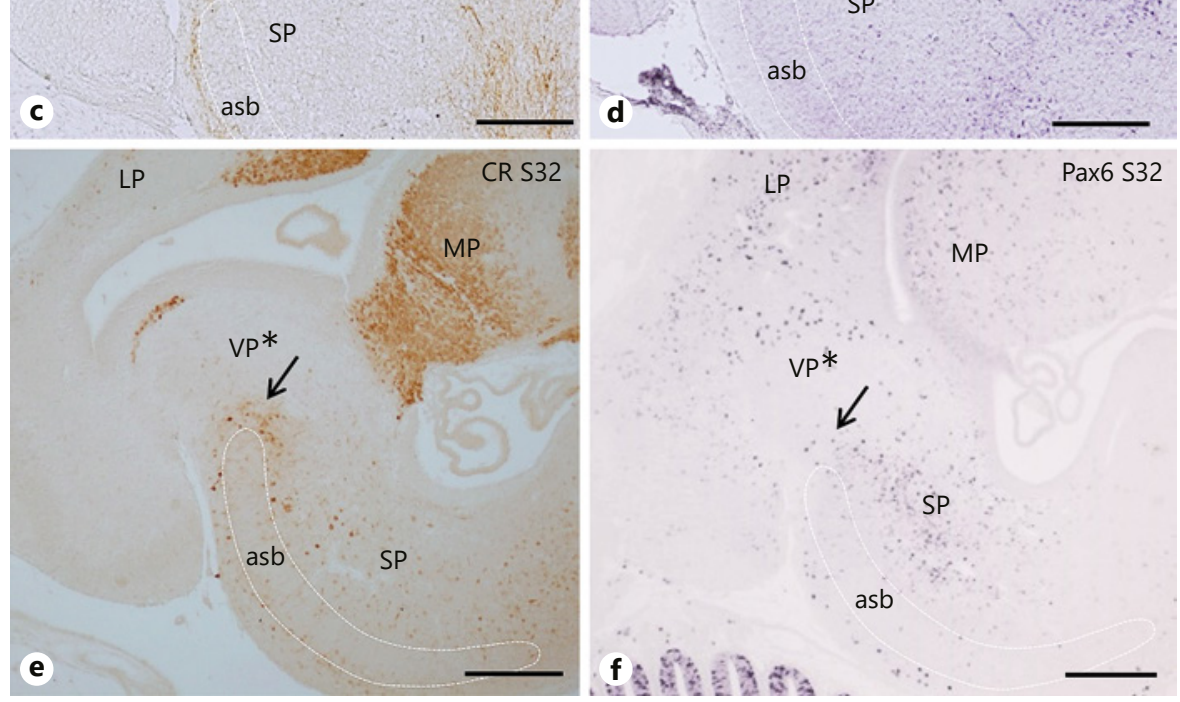

with carbocyanide dye (Fig. 2C-E in Yáñez et al. [2011]). Immunohistochemical staining also allowed discerning the differences among this region and the adjacent territories. The distribution of immunoreactivity to $5 \mathrm{HT}$ and $\mathrm{TH}$ is similar to that observed in the adult, which allows identifying the prospective pallial amygdalar territory in juveniles as the area lacking 5HT immunoreactivity (asterisk in Fig. 3c, d) that contains scarce TH-ir cells (asterisk in Fig. 3e, f). As in adults, TH-ir cells are radially distributed (white arrowheads in Fig. 3f). At this postnatal stage, the contrast in the distribution of other immunomarkers as $\mathrm{CB}$ and Pax6 also helps to characterize the supposed pallial amygdala territory as the area where CBir cells are lacking (asterisk in Fig. 3g, h) and Pax6-ir cells are scarce (asterisks in Fig. 3i-1), which contrasts with the abundant Pax6 of other pallial territories such as the lateral pallium (LP in Fig. 3i). The absence of CB immunoreactivity in the proposed pallial amygdala contrasts with the abundant CB-ir cells and fibers of the area superficialis basalis (asb in Fig. 3g, h). Interestingly, a few large CBir cells are capping the dorsal pole of the area superficialis basalis (arrow in Fig. 3g, h), and a conspicuous condensation of Pax6-ir cell is observed in a similar position (arrows in Fig. 3i-l) even at levels of the anterior commissure 

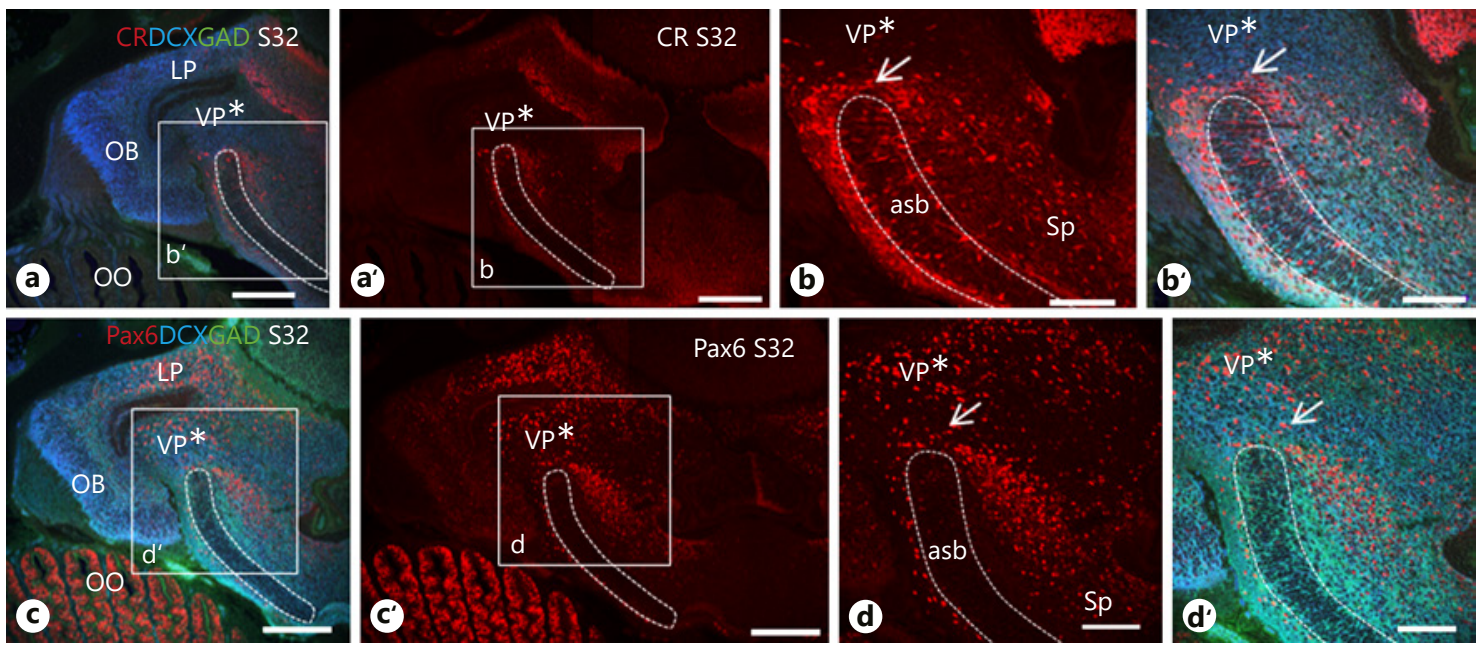

Fig. 6. Transverse sections through the telencephalon of stage-32 embryos (S32) of the catshark double labeled with the immunomarkers indicated. $\mathbf{a}$ and $\mathbf{c}$ are adjacent sections. The prospective pallial amygdala is indicated as VP*. Arrows in $\mathbf{b}, \mathbf{b}^{\prime}, \mathbf{d}$, and $\mathbf{d}^{\prime}$ point to CR-ir cells $\left(\mathbf{b}, \mathbf{b}^{\prime}\right)$ and Pax6-ir cells $\left(\mathbf{d}, \mathbf{d}^{\prime}\right)$ that are capping the area superficialis basalis (asb). Scale bar, $300 \mu \mathrm{m}\left(\mathbf{a}, \mathbf{a}^{\prime}, \mathbf{c}, \mathbf{c}^{\prime}\right), 150 \mu \mathrm{m}\left(\mathbf{b}, \mathbf{b}^{\prime}, \mathbf{d}, \mathbf{d}^{\prime}\right)$. For more abbreviations, see list.

and even caudally (topologically ventrally), roughly corresponding to the level of the Figure 1e, where the subpallium overlaps the alar hypothalamus.

We have also analyzed embryos from stage 32 (early prehatchings), when the basic mature structure of the telencephalon is progressively achieved and the cytoarchitecture and organization of the telencephalon is becoming highly similar to that of juvenile and adults. Given that the topography of the telencephalon in this early prehatching embryo is somewhat different to that of juveniles, the identification of the presumed amygdalar territory is more difficult. However, it is possible to differentiate pallial and subpallial territories at the lateral telencephalic walls by using the area superficialis basalis (subpallial) as reference, taking advantage of its high density, which allows to distinguish it by contrast even when none of its elements are stained (as in the micro-CT sections; asb in Fig. 4, 5a, b). As regards the adult brain, we used micro-CT imaging of a whole head of a S32 embryo for selecting sagittal, horizontal, and transverse sections through the lateral telencephalic wall, at the place where we estimate that the prospective pallial amygdalar territory is located (between levels shown in Fig. 4a and b). Again, we remark that the relative position of the telencephalic structures will be described in relation to the anterior-posterior, dorso-ventral, and medio-lateral axis defined according to the longitudinal head axis (not to the prosomeric forebrain axis).

The distinct labelling of the immunomarkers used in adults and juveniles has also contributed to characterize the prospective pallial amygdala region in these prehatching embryos. The distribution of 5HT immunoreactivity in these large embryos serves to distinguish the equivalent to the adult and juvenile pallial amygdala-like region as the immunonegative zone (VP* in Fig. 5c) dorsal to the abundant 5HT-ir innervation capping the dorsal pole of the area superficialis basalis (arrow in Fig. 5c). As in juveniles, CB-ir cells are absent in the proposed pallial amygdala (VP* in Fig. 5d) while a conspicuous group of $\mathrm{CB}$-ir cells are bordering the area superficialis basalis (arrow in Fig. 5d). The distribution of immunoreactivity to CR is similar to that of CB (Fig. 5e). The differential distribution of Pax6-ir cells shows that the supposed pallial amygdalar territory (VP* in Fig. 5f) presents less density of these cells than the adjacent lateral pallium (LP in Fig. 5f) and the borders of the area superficialis basalis (arrow in Fig. 5f). Although double labelling CR and Pax6 could not be performed because both antibodies were directed against rabbit, we have comparatively analyzed adjacent sections labelled for each of these antibodies (Fig. 6). Such comparison reveals that CR-ir cells and Pax6-ir cells codistribute in the region forming a cap around the dorsal margin of the area superficialis basalis (arrows in Fig. 6b, b', d, d'). Pax6-ir cells are absent in the area superficialis basalis proper, which in turn contains radially organized CR-ir cells. The analysis of the anteroposterior organization of the Pax6-ir cell population at the supposed pallial amygdala territory (VP* in Fig. 7a-c) reveals a heterogeneous distribution, even with vacant 

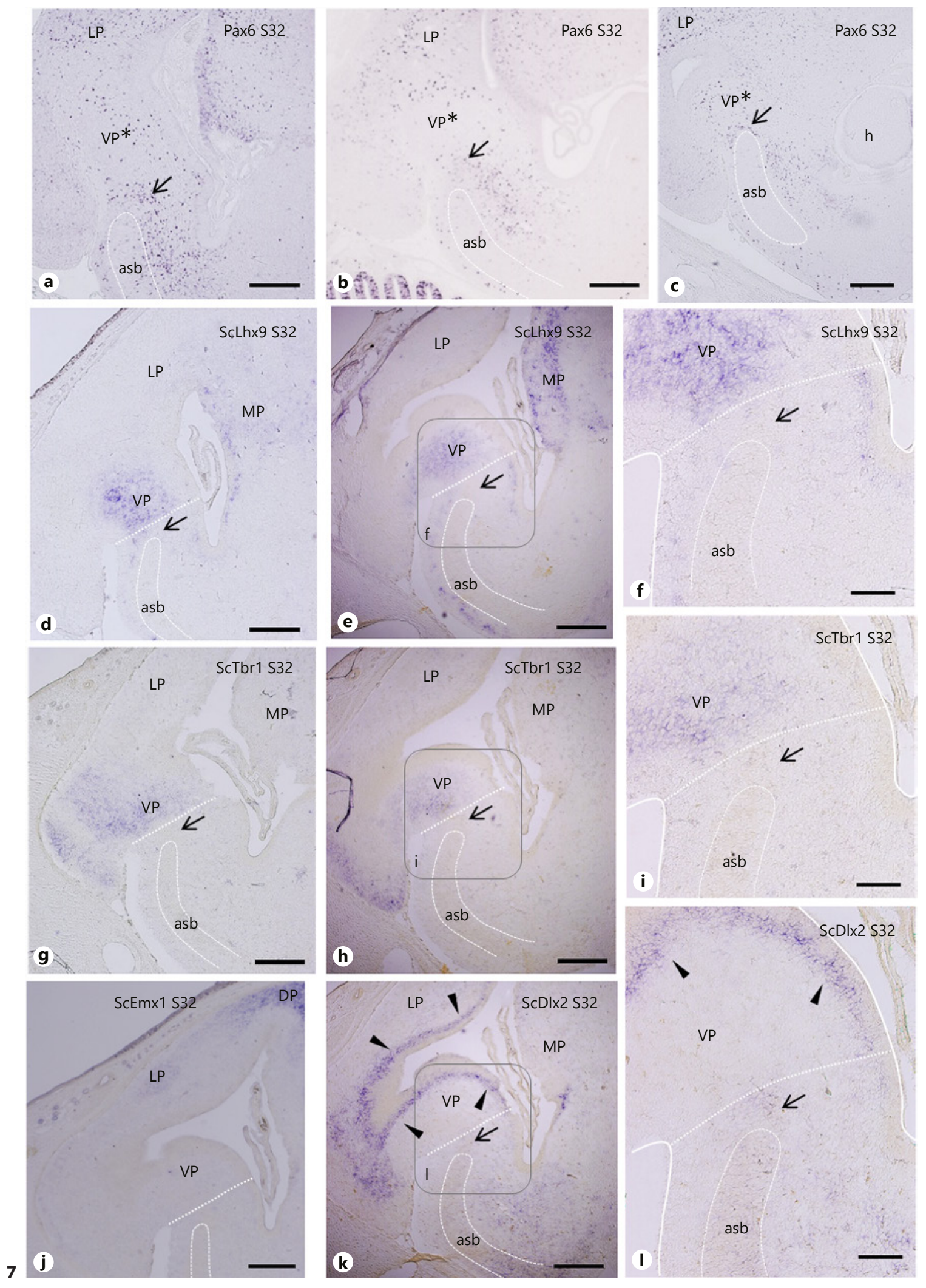

(For legend see next page.) 
spaces at some levels, which contrasts with the homogenous and dense Pax6 cell population that caps the area superficialis basalis at the different anterior to posterior levels analyzed (arrow in Fig. 7a-c).

To better determine pallial and subpallial divisions at the lateral hemispheric wall, we analyzed the differential expression patterns of genes known to be expressed in the pallium (ScLhx9, ScTbr1, ScEmx1) and in the subpallium (ScDlx2) of catshark embryos [Quintana-Urzainqui et al., 2012; 2015; Santos-Durán et al., 2016]. The detailed comparison of adjacent sections labelled for these markers clearly reveals the pallial-subpallial boundary as the ventral limit of the pallial expression of ScLhx9 and ScTbr1 and the dorsal limit of the subpallial $S c D l x 2$ expression (discontinuous radial line in Fig. 7f, i, 1). In addition, ScLxh9 and ScTbr1 genes are expressed in the mantle of the territory we propose as pallial amygdala (VP in Fig. $7 \mathrm{~d}-\mathrm{i}$ ) but not the ScEmx1 gene (VP in Fig. 7j), which in contrast is clearly expressed in the lateral and dorsal pallia (LP and DP, respectively, in Fig. 7j). Thus, the combinatorial expression of ScTbr1 and ScLhx9 genes in the presumptive pallial amygdala region, together with the absence of ScEmx1 expression, supports its identification as a ventral pallial territory. As reported previously [Quintana-Urzainqui et al., 2015], at this stage 32 there is an intense $S c D l x 2$ expression throughout the subventricular walls of the lateral ventricles corresponding to ventral and lateral pallia that contrasts with the lack of ex-

Fig. 7. Transverse sections through the telencephalon of stage- 32 embryos (S32) of the catshark showing the distribution of Pax6 immunoreactivity $(\mathbf{a}-\mathbf{c})$ and the expression of $\operatorname{ScLh} x 9(\mathbf{d}-\mathbf{f})$ and ScTbr1 (g-i) genes from rostral (left) to caudal (right) levels, and the expressions of $S c E m x 1(\mathbf{j})$ and $S c D l x 2(\mathbf{k}, \mathbf{I})$ at equivalent levels of panels $\mathbf{b}, \mathbf{e}$, and $\mathbf{h}$. The images $\mathbf{f}, \mathbf{i}$, and $\mathbf{I}$ are details of three adjacent sections showing ScLhx9 (f), ScTbr1 (i), and ScDlx2 (I). These details roughly correspond to the squared areas in $\mathbf{e}, \mathbf{h}$, and k. The prospective pallial amygdala in $\mathbf{a}-\mathbf{c}$ is indicated as VP*. The expressions of $S c L h \times 9$ and $S c T b r 1$ but not of $S c E m x 1$ in this region reveal characteristics of a ventral pallium (VP). The dotted radial line in $\mathbf{d}-\mathbf{I}$ represents the pallial-subpallial boundary. Note that this just coincides with the ventral limit of the $S c L h x 9$ (f) and ScTbr1 (i) domains and with the dorsal limit of the subpallial $S c D l \times 2$ expression (I). Arrows point to the region just dorsal to the area superficialis basalis (asb) that contains a conspicuous Pax6-ir cell population (a-c), some cells faintly expressing $S c L h \times 9$ (see detail in f) and $S c T b r 1$ (see detail in i), and a moderate amount of $S c D l \times 2$ expressing cells (see detail in I). Arrowheads in $\mathbf{k}$ and I point to intense $S c D l x 2$ expression throughout the subventricular pallial walls probably representing streams of subpallial-pallial migrating cells [Quintana-Urzainqui et al., 2015]. Scale bar, $500 \mu \mathrm{m}$ (a-e, $\mathbf{g}-\mathbf{h}, \mathbf{j}, \mathbf{k}), 200 \mu \mathrm{m}(\mathbf{f}, \mathbf{i}, \mathbf{I})$. For more abbreviations, see list.

The Catshark Pallial Amygdala pression in the mantle of these pallial regions (arrowheads in Fig. $7 \mathrm{k}, 1$ ). These pallial subventricular $S c D l x 2$-expressing cells represent streams of subpallialpallial migrating cells [Quintana-Urzainqui et al., 2015]. The expression of $S c D l \times 2$ is absent in the mantle of any pallial territory but this gene is expressed in different subpallial regions.

The comparison of the Pax6 distribution at three anterior-posterior levels (Fig. 7a-c) with the expression pattern of ScLxh9 (Fig. 7d-f) and ScTbr1 (Fig. 7g-i) genes at equivalent telencephalic levels reveals that the Pax6 population described in the proposed pallial amygdala ( $\mathrm{VP}^{*}$ in Fig. $7 \mathrm{a}-\mathrm{c}$ ) is comparable molecularly to ventropallial populations. Interestingly, such comparison in the subpallial territory adjacent to the pallial-subpallial boundary reveals that the Pax6 cell group that is capping the area superficialis basalis (arrows in Fig. 7a-c) occupies a territory that presents cells with a faint expression of the ventropallial markers ScLxh9 and ScTbr1 (arrows in Fig. 7f and i, respectively) and cells with a moderate expression of the subpallial marker $S c D l x 2$ (arrow in Fig. 7k, l).

\section{Discussion/Conclusion}

\section{Catshark Telencephalic Subdivisions}

Two main histogenetic subdivisions, the pallium and the subpallium, which includes the preoptic area, are recognized in the telencephalon of the catshark. Such basic telencephalic territories appear to be specified by similar sets of developmental regulatory genes as in other vertebrates and they are subdivided in similar ways [Quintana-Urzainqui et al., 2012]. In the developing catshark telencephalon, the position of the pallial-subpallial boundary has been defined by the expression of Pax6 and ScTbr1 in the pallium, and ScDlx2 and GAD in the subpallium, but in adults this limit is not easy to recognize. Previous developmental studies in this species have shown evidence of the existence of four different histogenetic pallial territories (medial, dorsal, lateral, and ventral pallia) defined on the basis of the differential expression of ScTbr1, ScEmx1, and ScLhx9 genes [QuintanaUrzainqui et al., 2012, 2015; Santos-Durán et al., 2015, 2016; Rodríguez-Moldes et al., 2017]: the ScTbr1/ScLhx9/ScEmxla-negative dorsal pallium, the ScTbr1/ ScEmx1/ScLhx9-positive medial pallium, the ScEmx1/ ScTbr1/ScLhx9-positive lateral pallium, and the ScTbr1/ ScLhx9-positive and ScEmx1-negative ventral pallium. These developmental studies in the catshark have also contributed to identify two subpallial histogenetic terri-

Brain Behav Evol 2021;96:283-304 
tories probably equivalent to the medial and lateral ganglionic eminences of mammals (MGE and LGE, respectively) that give rise to the pallidum and striatum, respectively: the $\mathrm{ScDlx} 2 / \mathrm{ScNkx} 2.1$-positive medial prominence in the midline (MGE-like), and the ScDlx2-positive and ScNkx2.1-negative lateral prominence (LGE-like), from which the components of the catshark basal ganglia derivate.

The present work not only supports our previous proposal that the region dorsal to the area superficialis basalis corresponds to an amygdala-like structure in this species [Quintana-Urzainqui et al., 2012], but also advances in its knowledge thanks to the characterization of the pallial components based on data obtained in adults, juveniles, and embryos at stage 32 .

Topographic Localization of the Pallial Amygdala in Catshark - Related Adjacent Territories: the Striatal Protrusion and the Area Superficialis Basalis

The territory we have proposed as the catshark pallial amygdala occupies the region lateral to the Smeets' striatum, dorsal to the area superficialis basalis, and ventrocaudal to the insertion of the olfactory bulb and the retrobulbar area, and it extends from a level caudal to the insertion of the olfactory bulb to the level of the anterior commissure. Smeets et al. [1983], who described in detail the organization of the mature forebrain (and other brain regions) in representatives from four groups of chondrichthyans including Scyliorhinus canicula and Squalus acanthias as representatives of galeomorph and squalomorh sharks, respectively, did not provide any reference to the possible existence of amygdaloid territories in chondrichthyans. Moreover, the region of S. canicula studied here appeared unnamed in the cited work by Smeets et al., which is largely used as the reference atlas for adult chondrichthyan brains. The present study shows that it is a pallial territory that presents characteristics of the ventral pallial amygdala (see below) that differentiates this region from the adjacent territories.

The supposed pallial amygdala territory is lateral to the rather distinct protrusion in the ventrolateral walls of the Scyliorhinus telencephalon, which contains a conspicuous cell mass that has been identified as the "striatum" by Smeets et al. [1983]. It presents a laminar structure with a characteristic S-shaped disposition (in cross section). The periventricular area of this region shows abundant $\mathrm{TH}$-ir cells in a rather dense $\mathrm{TH}$-ir neuropile, but they were not observed in the equivalent region of embryos at stage 32 [Carrera et al., 2012; Quintana-Urzainqui et al., 2012; present results].
The territory proposed as the catshark pallial amygdala extends up to a distinct region that borders the dorsal part of the area superficialis basalis. This subpallial cells mass is well recognized in all chondrichthyans because of the characteristic arrangement of its small cells forming a $U$-shaped layer that occupies the ventral outer zone of the subpallium. It received other names, as hypostriatum, nucleus taeniae, or tuberculum olfactorium by classic authors (revised in Smeets et al. [1983]). In Scyliorhinus this domain is very large in rostrocaudal extent and its high cellular density is evident even on the micro-CT images, especially in embryos (see Fig. 1 and 3). Its equivalence to a particular subpallial structure in other vertebrates is under debate. It was proposed to be homologous to the pallidal subpallium in S. canicula [Carrera et al., 2012], as in other chondrichthyans, although it shows characteristics of the olfactory tubercle (ventral striatum), as was recognized in Squalus [Holmgren, 1922; Northcutt et al., 1988]. Moreover, the possibility that area superficialis basalis populations have mixed origins from both the lateral and medial ganglionic eminence homologs has been suggested based on the evidence of cell migratory routes in the subpallium of late catshark embryos [Quintana-Urzainqui et al., 2015]. Anyway, there is agreement that the area superficialis basalis represents a subpallial territory.

\section{The Catshark Pallial Amygdala and Olfactory}

\section{Projections}

The area topographically identified in the catshark as the pallial amygdala is related to olfaction as it is recipient of secondary olfactory fibers, as demonstrated by Smeets [1983] in adults and by Yáñez et al. [2011] in juveniles of Scyliorhinus. Experiments in adults showed that it is the place of termination of most of olfactory secondary fibers that coursed in the tractus olfactorius lateralis, as shown by experiments of degeneration after unilateral lesions of the olfactory bulb (Fig. 2D, E of Smeets et al. [1983]). Experimental tracing methods applied to the olfactory bulb of juveniles using carbocyanine dyes also revealed bulbar projections to a lateral region of the pallium that they identified as the retrobulbar region (Fig. 2C, D of Yáñez et al. [2011]), although these projections appeared to be scarcer than those described in adults by Smeets [1983].

Both Smeets [1983] and Yáñez et al. [2011], although using different experimental methods, also showed in $S$. canicula another area of the lateral hemispheric walls that receives abundant olfactory projections, namely the superficial region of the area superficialis basalis. At least in part, this region roughly corresponds to the territory bordering the dorsal pole of the area superficialis basalis, a 
region that receives prominent secondary olfactory projections also in other elasmobranch species [Smeets, 1983; Dryer and Graziadei, 1994; Hofmann and Northcutt, 2008; Yáñez et al., 2011].

Taking together these observations and present results, it seems clear that there are two different olfactory projection recipient regions in the lateral telencephalic wall of Scyliorhinus. One represents a clearly pallial region that we consider a ventral pallial amygdalar part, and the other lies at the pallial-subpallial interface and is closely related to the area superficialis basalis (a subpallial structure). These either olfactory-related or pallialsubpallial-boundary-related territories form part of the pallial amygdala. The second may instead belong to a subdivision of the subpallial amygdala (see below).

Developmental studies about the secondary olfactory projections in chondrichthyans are not yet available. However, indirect support may be inferred through the comparison of catshark S32 embryos with the equivalent embryonic stage of Squalus, the embryos of $8 \mathrm{~cm}$, characterized by Holmgren [1922] after studying cresyl violet stained sections, as the embryonic stage where "the definitive arrangement of the forebrain is attained." Holmgren described a "lateral olfactory nucleus" as a "great cellular condensation with somewhat cortical aspect, dorsal to the lateral border of the tuberculum olfactorium," which corresponds to the area superficialis basalis (see above). Moreover, though Holmgren identified the nucleus olfactorius lateralis as part of the subpallium, its definition of this nucleus in Squalus embryos of $5 \mathrm{~cm}$ clearly corresponds to the area we identified as ventral pallium in catshark embryos at stage 31 [Rodríguez-Moldes, 2009; Rodríguez-Moldes et al., 2017]. This territory was interpreted as the lateral pallium of the classic tripartite pallium model before the fourth pallial subdivision, the ventral pallium, was recognized in developmental genoarchitectonic studies in catsharks (see above). Such studies led to identify the novel reduced lateral pallium as derived from the laterodorsal wall of the embryonic pallium (revised in Rodríguez-Moldes et al. [2017]). Consequently, the pallium lateralis defined by Smeets et al. [1983] in adults of Scyliorhinus should be considered, at least in part, to correspond to the region identified here as ventral pallium (see below).

In Squalus, an olfaction-related nucleus was recognized as nucleus A ventral to the lateral pallium and dorsolateral to the area superficialis basalis by Northcutt [Northcutt, 1978; Northcutt et al., 1988]. We think that, at least in part, the nucleus A of Squalus adults (a pallial nucleus according Northcutt et al. [1988]), the nucleus olfactorius lateralis of Squalus embryos (a subpallial nucleus according to Holmgren [1922]), the olfactory-recipient lateral pallium of Scyliorhinus [Smeets, 1983; Smeets et al., 1983], and the ventral pallium of embryos, juveniles, and adults of Scyliorhinus (present results) all are olfactory-recipient areas that represent the pallial amygdala. We consider it a different sort of amygdalar territory than the territory that caps the dorsal part of the area superficialis basalis, which might represent another subdivision of the pallial amygdala (a ventrolateral subdivision within the ventropallial amygdala) or a pallial cellular contingent within a subpallial amygdalar subdivision (perhaps equivalent to the medial amygdala of amphibians, see below). This amygdala-like territory could also be related to the mammalian nucleus of the lateral olfactory tract, a superficial migrated pallial amygdalar nucleus that receives olfactory input, situated within the subpallial anterior amygdala [Garcia-Calero et al., 2021].

\section{Chemoarchitecture of the Catshark Pallial Amygdala}

The existence of abundant TH-ir cells is a distinctive characteristic of the chondrichthyan pallium (revised in Carrera et al. [2012]). In the catshark, it has been reported that such pallial TH-ir cells develop at stage 31, earlier than the subpallial ones, and that they already form an abundant population in S32 embryos [Carrera et al., 2012]. TH-ir cells have also been described in the ventrolateral wall of the pallium of juveniles and adults (Fig. 9E of Carrera et al. [2012] and present results). The dorsal and lateral pallia of adult catsharks also contain SOM-ir cells (not shown) in agreement with results in other shark species [Chiba et al., 1989]. Numerous scattered somatostatinergic cells (expressing prosomatostatin genes), many of them exhibiting $\mathrm{TH}$ immunoreactivity too, have been recently reported in the pallium of the catshark juveniles [Sobrido-Cameán et al., 2020], but presomatostatin-expressing cells are nearly absent in their lateroventral walls (see Fig. 1d, e of Sobrido-Cameán et al. [2020]). SOM-ir and TH-ir cells in the lateral wall present the characteristic small size of the catecholaminergic and somatostatinergic cells of the pallial adjacent region, abundantly occupying also the lateral (ventral) pallium [Carrera et al., 2012; Sobrido-Cameán et al., 2020]. Interestingly, the $\mathrm{TH}$-ir cells of the ventrolateral hemispheric wall present a characteristic radial distribution, possibly related to the pallial-subpallial boundary. That this lateroventral telencephalic region (the mantle) is a pallial derivative is also supported by the differences with adjacent subpallial territories such as the ventrolateral periventricular walls (the striatal protrusion) and the area superficialis basalis, 
which have been related to the basal ganglia of amniotes because of their TH-ir innervation [Carrera et al., 2012]. The region identified as pallial amygdala in catshark does not contain 5HT-ir nor MetENK-ir cells. Such cells likewise were not observed in the subpallium, which characteristically contains abundant 5HT-ir and MetENK-ir fibers, especially bordering the dorsal cap of the area superficialis basalis [Carrera et al., 2008; Quintana-Urzainqui et al., 2012]. The density of 5HT fibers and boutons was particularly high in adults, juveniles, and prehatching embryos at the dorsolateral margin of the area superficialis basalis [Carrera et al., 2008; present results].

At all telencephalic levels at the stages studied (late embryos, juveniles, and adults), Pax6-ir cells are abundant in the pallium and sparse in the subpallium [Rodríguez-Moldes, 2009; Ferreiro-Galve et al., 2012; Quintana-Urzainqui et al., 2012, 2015; present results]. Developmental studies in the catshark revealed spatiotemporal differences in the Pax6-ir cell distribution. In early embryos, when no layering is observed in the telencephalic walls, Pax6 cells are abundant in the pallium but absent in the subpallium, but later, when the wall presents the characteristic three-layered organization, the first Pax6-ir in the subpallium, probably migrating cells, were noticed concurrently with the formation of olfactory bulbs, which emerge as protrusions from a lateral/ventral pallial region that was practically devoid of Pax6-expressing cells in contrast with the rest of the pallium. This pallial Pax6-ir-negative region adjacent to the incipient olfactory bulb was tentatively identified as a ventral pallium [Rodríguez-Moldes, 2009]. The equivalent zone at $\mathrm{S} 32$ can be identified as a ventral pallium based on the expression of developmental regulatory genes (see below) and contains Pax6-ir cells in a heterogeneous distribution either in radial (medial to lateral) and longitudinal (rostral to caudal) planes. We interpreted that this population belongs to the catshark pallial amygdala and perhaps represents a subdivision derived from or continuous with the cortical ventral pallium.

In addition to this Pax6-ir cell group, we are intrigued about the conspicuous Pax6-ir cell group bordering dorsally the area superficialis basalis, a position clearly related to the cap-like patch of 5HT-ir fibers (and CR-ir cells and fibers) at the same location. This cap-like patch forms a neurochemically heterogeneous structure containing 5HT-ir, MetEnk-ir, CB-it, CR-ir, and Pax6-ir cells and/or fibers. Because of its topography, its chemical heterogeneity, its relation to olfactory secondary projections (see above), and its position closely related to a subpallial structure like the area superficialis basalis, it could be considered a subdivision of the subpallial amygdala.
Ventropallial Origin of the Catshark Pallial Amygdala

The ventral pallial domain has been defined as the ventralmost aspect of the pallium in which $E m \times 1$ is not expressed, just in direct contact to the pallial-subpallial boundary [Fernández et al., 1998; Puelles et al., 2000; Bachy et al., 2002; Brox et al., 2004]. It was previously included within the lateral pallium, but now it is considered to represent a distinct radial pallial domain that expresses Emx 1 and Tbr 1 and gives rise to the piriform cortex and parts of the pallial amygdala in mammals [Medina and Abellán, 2009; Puelles et al., 2016]. The ventral pallial domain has been characterized by its topological position and the ventricular zone expression of Pax6, the mantle expression of Tbr1/Tbr2, and the absence of Emx1 and Dlx2 expressions in the ventricular and mantle zones (reviewed in Medina et al. [2017]). Moreover, the expression of Lhx9 in the mantle of the caudal aspect of the ventral pallium has been related to the ventral pallial amygdala [Abellán et al., 2009], though Garcia-Calero and Puelles [2021] consider that it characterizes only one of the radial units of the mouse pallial amygdala, the anterior unit, which forms the basomedial anterior nucleus, the anterior cortical nucleus, and contributed abundant migrating cells to the subpallial anterior amygdala.

Previous developmental studies in catshark embryos at stage 31, which is considered the mid-neurogenesis state of catshark telencephalic development [QuintanaUrzainqui et al., 2015], provided data that distinguish in this species lateral and ventral pallial subdivisions equivalent to those of tetrapods, based on the differential expression of developmental regulatory genes. Thus, the $T b r 1+/ L h \times 9+/ E m \times 1-$ territory was identified as ventral pallium while the lateral pallium corresponded to a discrete Emx1-expressing domain within the Tbr1+/Lhx9+ territory located dorsally to the ventral pallium. The present study shows that at $\mathrm{S} 32$, the stage when the maturation of the telencephalic centers begins and the main telencephalic populations are settled, the expression of such genes remains as in previous developmental stages, making it possible to differentiate these pallial subdivisions.

Our observations, thus, strongly support the existence of a ventral pallial domain in the brain of $S$. canicula showing the main features described in amniotes (that is, Tbr 1 and $L h \times 9$ expression and absence of Emx1 expression), which allows to accurately delimit the extent of this domain.

The combinatorial comparative analysis of the neurochemical and genetic markers revealed that the shark 
amygdalar territory comprises a pallial amygdala portion derived from or continuous with the ventral pallium. As noted in the previous sections and after comparing the chemoarchitecture in this area in S32, we can state that the ventral pallium contains a moderate amount of TH-ir, SOM-ir, and Pax6-ir cells. The same pattern was observed in juveniles and adults of Scyliorhinus and matches with the distribution of these markers in the other vertebrates (see below).

\section{Amygdala in Chondrichthyans}

As far as we know, the only attempt to identify amygdalar territories in chondrichthyans was performed in the squalomorph Squalus acanthias independently by Williams [1973] and by Northcutt et al. [1988]. In Williams' article, he analyzed the microscopic anatomy of the telencephalon of newborn Squalus, a shark that at that time was the reference shark species for neuroanatomical studies. Williams did not propose homologies but directly named the different telencephalic territories similarly to those of other vertebrates, mainly mammals, based only on their topographical position. He considered that the amygdala of Squalus was included in the caudal portion of the primordial hippocampal formation of Johnston [1911] (thus considered exclusively pallial) and subdivided it into three components, anterior, corticomedial, and basolateral amygdaloid divisions, as described for other nonmammalian forms by Schnitzlein et al. [1967]. The primordial anterior amygdaloid division was defined by Williams as a region of poorly defined rostrocaudal boundaries located at the ventral portion of the lateral wall of the telencephalic hemisphere, and the primordial corticomedial amygdaloid division was a region at the lateral wall of the hemisphere that receives fascicles from the lateral olfactory tract and from the nucleus of diagonal band (= interstitial nucleus of the basal forebrain bundle, a subpallial nucleus at the telencephalic peduncle according to Smeets et al. [1983]). The primordial basolateral amygdaloid division of Williams was defined as the region that forms most of the dorsal hemispheric wall and corresponds to the pars caudalis of the dorsal pallium of Smeets et al. [1983].

In 1988, in a study performed in the adult telencephalon of Squalus, Northcutt et al. sustained that a nucleus that they called nucleus A, which received secondary olfactory fibers and was located ventral to the lateral pallium and dorsolateral to the area superficialis basalis, could be the possible homolog of the pallial amygdala of land vertebrates. Northcutt et al.'s proposal referred to a scattered cell group, pallial in origin, located as the ventral continuation of the lateral pallium that receives secondary olfactory fibers and which could be traced caudally to where it replaces the area superficialis basalis. The nucleus A was immunohistochemically characterized by its low density or absence of ENK+, SP+, and $\mathrm{TH}+$ neurons and fibers and by the reception of an extensive olfactory input via the lateral olfactory tract [Bodznick and Northcutt, 1979].

Based on observations in Squalus acanthias and the present results in Scyliorhinus canicula, we conclude that there exists an amygdalar structure in chondrichthyans containing several nuclear groups that may be components of a primordial amygdalar complex. Some coincidences in the descriptions of both works and our observations in the catshark lead us to identify a pallial amygdalar territory at the lateral wall of the telencephalic territory that receives olfactory fibers. In Squalus this territory corresponds, at least in part, to William's anterior amygdalar division and to Northcutt's nucleus A, whereas in Scyliorhinus it corresponds to the ventropallial region that neurochemically contains some Pax6-ir, $\mathrm{TH}$-ir, and SOM-ir cells but not CR immunoreactivity, at difference from the adjacent territories (present results).

Behavioral studies using different elasmobranch species (revised in Schluessel [2015]) revealed that chondrichthyans may share the cognitive skills found in teleost and other vertebrates. Although the neural substrate which underlies cognitive functions has not been identified, it was suggested that the lateroventral region of the classic tripartite lateral pallium (our ventral pallium) and regions close to the subpallial area superficialis basalis may be structures involved in cognitive functions such as avoidance learning and fear conditioning [Schwarze et al., 2013; Schluessel, 2015; Fuss and Schluessel, 2018]. However, this region appeared not to be a neural substrate involved in learning and memory retention with respect to visual discrimination tasks in the bamboo shark (Chiloscyllium griseum), at least when the differential expression of the neuronal marker egr-1 was used to measure the response to certain test conditions [Fuss and Schluessel, 2018]. Association between the test condition and egr-1 expression levels were instead found in a subpallial region of this species identified as "ventral to the ventriculus impar telencephalic," which has been interpreted as indicative of activation of this area during learning and memory retention. Whether this region at the ventrolateral part of the subpallium is related to the subpallial amygdala should be further analyzed. 


\section{Comparison with Other Vertebrates}

The amygdalar complex of tetrapods has been subdivided in pallial and subpallial divisions based on the developmental origin of their components: the pallial amygdala formed by derivatives of the ventral and lateral pallium, and the subpallial amygdala formed by derivatives of the lateral and medial eminences (revised in Moreno and González [2007a], Medina et al. [2011, 2017]). Moreover, the comparative analysis of its organization, mainly its connections and main functional systems, has led to propose three amygdalar basic subdivisions that would be present in the ancestral tetrapods [Moreno and González, 2006]: the LA as the subdivision within the ventral pallium (the only component of the pallial amygdala that receives secondary olfactory fibers); the medial amygdala, the vomeronasal component, at the level of the postcommissural preoptic area that contains both pallial and subpallial contributions, receives afferents from the accessory bulb, and projects to the hypothalamus; and the central amygdala, at the caudal pole of the striatal region (subpallial amygdala) mainly related to autonomic functions. This ancestral condition would not include any subdivisions in the pallial amygdala. However, in amniotes, several components have been recognized. In mammals, a superficial group of nuclei with a laminar organization, the cortical amygdala, and a deep group of nuclei that form the basolateral amygdala, which includes lateral, basolateral, and basomedial amygdalar nuclei [Swanson and Petrovich, 1998] arising from the ventral pallium and the lateral pallium [Puelles et al., 2000; Medina et al., 2004,2011 ] have been considered. The amphibian LA is considered related to the amygdaloid ventropallial derivatives of the basolateral complex of amniotes [Moreno and González, 2004, 2007b] but the only pallial amygdaloid component in amphibians [Bandín et al., 2014]. However, the pallial amygdala of zebrafish $(\mathrm{Dm})$ has been molecularly subdivided into anterior and posterior parts [Porter and Mueller, 2020]. In addition, within the zebrafish Dm, a subpopulation of glutamatergic neurons (named 120A-Dm) has been identified that is essential for fear conditioning, and therefore it has been proposed to be a functional equivalent to the mammalian pallial amygdala, specifically to the basolateral amygdala [Lal et al., 2018].

In this work we have identified the catshark telencephalic territory found ventral to the lateral pallium and dorsolateral to the area superficialis basalis as the ventral pallial component of the amygdalar complex characterized by the lack of subpallial markers, its relationship with olfactory fibers, and its chemical signature, defined by a moderate density of Pax6-ir cells, the presence of scarce $\mathrm{TH}$-ir and SOM-ir cells, and by the absence of CR-ir (and CB-ir) cells. Because of its topography, ventropallial origin, olfactory relationship, and neurochemical features, this telencephalic territory is comparable to the LA of amphibians [Marín et al., 1998; Moreno and González, 2004, 2006, 2007a, b; González et al., 2017; Morona and González, 2008] and lungfish [González and Northcutt, 2009; López et al., 2017, 2020; Morona et al., 2018] and to the region viewed as the pallial amygdala of teleost, identified as the dorsomedial subdivision of the pallium [Mueller et al., 2011; Porter and Mueller, 2020; Gerlach and Wullimann, 2021] although some differences can be pointed out. The presence of Pax6 cells in the pallial amygdala appears to be a characteristic shared by anuran and urodele amphibians [Joven et al., 2013a, b; Bandín et al., 2014], lungfish [López et al., 2020], catshark (present results), and mammals [Puelles et al., 2000; Medina et al., 2011; Duan et al., 2013], but differences in density are noted. While these cells are abundant in the LA of urodeles [Joven et al., 2013a, b] and lungfish [López et al., 2020], their density in the catshark is moderate in comparison with the adjacent territories (lateral pallium and the region bordering the dorsal cap of the area superficialis basalis). Instead, results in catshark agree with that reported in mammals, where small numbers of Pax6 cells have been reported in mouse embryos and adults in components of the pallial amygdala mainly related to the basolateral complex [Medina et al., 2011; Duan et al., 2013]. The absence of CR-ir and CB-ir cells in the ventropallial amygdala of the catshark contrasts with the abundance of these cells in amphibians and lungfish [Morona and González, 2008; López et al., 2020]. CB-ir and, in a lesser extent, CR-ir cells have been used as markers to assess the precise location of the LA in amphibians and lungfish [Morona and González, 2008; López et al., 2020], but differences in the CB-ir and CR-ir cell distribution in the LA have been noted in amphibians [Morona and González, 2008]. Differences were also noted with respect to the distribution of $\mathrm{TH}+$ cells, which were absent from the LA of amphibians and lungfishes [Morona and González, 2008; López et al., 2020]. Expression of the TH gene has been observed in the pallial amygdala of mouse, mostly located in the anterior cortical amygdalar area [Bupesh et al., 2014].

In the catshark, in addition to the counterpart of the amphibian LA, we have identified another telencephalic region that could also be related to the amygdala. It is a neurochemically heterogeneous nuclear group that contains abundant Pax6-ir and CR-ir cells and abundant 
5HT-ir and MetEnk-ir fibers located adjacent to the pallial-subpallial boundary capping a subpallial structure as the area superficialis basalis. This pallial-subpallial boundary-related area also receives olfactory projections (see Fig. 2D of Smeets [1983] and Fig. 2D of Yáñez et al. [2011]). This conspicuous Pax6 cell population is related to the characteristic Pax6 cellular aggregate that forms the pallial-subpallial boundary from early developmental stages onwards [Ferreiro-Galve et al., 2008; Rodríguez-Moldes, 2009; Quintana-Urzainqui et al., 2012, 2015] and with that described in different sarcopterygians related to the amygdalar complex [Brox et al., 2004; Moreno and González, 2004; Moreno et al., 2008; Medina et al., 2017]. It has been noted that these Pax6 cells from the pallial-subpallial boundary migrate to specific emerging amygdaloid nuclei and other basal telencephalic structures (revised in Moreno et al. [2014]). In anuran amphibians, these cells form part to the pallial LA described above [Brox et al., 2004; Moreno and González, 2004] but such cells have been also described in subpallial amygdalar subdivisions as the medial and central amygdala [Bandín et al., 2014]. With the present data, we consider this catshark population related to the pallial-subpallial boundary as a subdivision of the subpallial amygdala, perhaps a dorsal subdivision of the medial amygdala. This catshark presumptive amygdalar population could be related to the dorsal part of the medial amygdala of zebrafish, which receive olfactory fibers from the main olfactory epithelial input via main olfactory bulb [Porter and Mueller, 2020] and with the medial amygdala of amphibians, which contains strongly intermingled populations of neurons with different embryonic origin [Moreno and González, 2007c]. Moreover, subpopulations of cells that express Lhx 9 and Tbr 1 coming from the ventral pallium have been reported in subdivisions of the subpallial amygdala of mammals as the medial amygdala [Medina et al., 2017]. So, the medial amygdala is currently considered a subpallial area that also contains pallial components although whether it is a pallial or a subpallial derivative has been a matter of debate [Moreno and González, 2006, 2007a].

Thus, the possibility that this catshark population is a subdivision of the pallial amygdala could be also considered. It could be suggested that there is a relation with the posterior pallial amygdaloid zone (PMPa) of zebrafish, a territory at the caudalmost Dm proposed as homolog of the mammalian posteromedial cortical amygdaloid nucleus [Porter and Mueller, 2020], but the present data are insufficient to sustain this equivalence. Further studies characterizing the subpallial amygdalar subdivisions will complement the present study.

The Catshark Pallial Amygdala

\section{Conclusions}

This study, together with the available data about the olfactory projections in chondrichthyan and with the observations by Williams [1973] and by Northcutt et al. [1988] in Squalus (which first evaluated the possible existence of certain amygdala-related nuclei within the pallium), supports the existence of a territory at the lateral walls of the telencephalic hemispheres of the catshark that presents characteristics compatible with a pallial amygdala equivalent to the ventropallial derivatives of the amygdala of tetrapods and a subpallial territory related to the pallial-subpallial boundary that apparently contains cells of ventropallial origin, perhaps representing a subdivision of the subpallial amygdala. More studies, especially hodologic ones, are needed to advance the present assessment of the amygdalar complex of chondrichthyans.

\section{Statement of Ethics}

The original research reported herein was performed according to the regulations and laws established by the European Union (2010/63/UE) and by the Spanish Royal Decree 1386/2018 for the care and handling of animals in research and were approved by the Ethics Committee of the University of Santiago de Compostela (15004AE/11/FUN 01/ANAT 01/ IRMR1).

\section{Conflict of Interest Statement}

The authors have no conflicts of interest to declare.

\section{Funding Sources}

This work was supported by Ministerio de Economía, Industria y Competitividad - Agencia Estatal de Investigación (grant No. BFU2017-89861-P) partially financed by the European Social Fund, and by Xunta de Galicia (grant No. ED431C 2021/18).

\section{Author Contributions}

G.N.S.-D., I.Q.-U., S.F.-G. led the experimental part, S.P.G. and M.C. generated the micro-CT imaging. S.M. provided the probes for in situ hybridization experiments. I.R.-M. wrote the article, further supplemented by E.C., who prepared the figures and created the final version. All authors approved the article.

\section{Data Availability Statement}

All data generated or analyzed during this study are included in this article. Further enquiries can be directed to the corresponding author. 


\section{References}

Abellán A, Legaz I, Vernier B, Rétaux S, Medina L. Olfactory and amygdalar structures of the chicken ventral pallium based on the combinatorial expression patterns of LIM and other developmental regulatory genes. J Comp Neurol. 2009 Sep;516(3):166-86.

Anadón R, Molist P, Pombal MA, RodríguezMoldes I, Rodicio MC. Marginal cells in the spinal cord of four elasmobranchs (Torpedo marmorata, T. torpedo, Raja undulata and Scyliorhinus canicula): evidence for homology with lamprey intraspinal stretch receptor neurons. Eur J Neurosci. 1995 May;7(5):93443.

Bachy I, Berthon J, Rétaux S. Defining pallial and subpallial divisions in the developing Xenopus forebrain. Mech Dev. 2002 Sep;117(12):163-72.

Ballard WW, Mellinger J, Lechenault H. A series of normal stages for development of Scyliorhinus canicula, the lesser spotted dogfish (Chondrichthyes: scyliorhinidae). J Exp Zool. 1993;267(3):318-36.

Bandín S, Morona R, López JM, Moreno $\mathrm{N}$, González A. Immunohistochemical analysis of Pax6 and Pax7 expression in the CNS of adult Xenopus laevis. J Chem Neuroanat. 2014 May;57-58:24-41.

Bardet SM, Cobos I, Puelles E, Martínez-De-LaTorre M, Puelles L. Chicken lateral septal organ and other circumventricular organs form in a striatal subdomain abutting the molecular striatopallidal border. J Comp Neurol. 2006 Dec;499(5):745-67.

Biechl D, Tietje K, Ryu S, Grothe B, Gerlach G, Wullimann MF. Identification of accessory olfactory system and medial amygdala in the zebrafish. Sci Rep. 2017 Mar;7(1):44295.

Bodznick D, Northcutt RG. Some connections of the lateral olfactory area of the horned shark. Abstr Soc Neurosci. 1979;5:139.

Braford MR Jr. Comparative aspects of forebrain organization in the ray-finned fishes: touchstones or not? Brain Behav Evol. 1995;46(45):259-74.

Braford MR Jr. Stalking the everted telencephalon: comparisons of forebrain organization in basal ray-finned fishes and teleosts. Brain Behav Evol. 2009;74(1):56-76.

Brox A, Ferreiro B, Puelles L, Medina L. The telencephalon of the frog Xenopus based on calretinin immunostaining and gene expression patterns. Brain Res Bull. 2002 Feb-Mar 1;57(3-4):381-4.

Brox A, Puelles L, Ferreiro B, Medina L. Expression of the genes Emx1, Tbr1, and Eomes (Tbr2) in the telencephalon of Xenopus laevis confirms the existence of a ventral pallial division in all tetrapods. J Comp Neurol. 2004 Jul;474(4):562-77.

Bupesh M, Vicario A, Abellán A, Desfilis E, Medina L. Dynamic expression of tyrosine hydroxylase mRNA and protein in neurons of the striatum and amygdala of mice, and experimental evidence of their multiple embry- onic origin. Brain Struct Funct. 2014 May; 219(3):751-76.

Carrera I, Anadón R, Rodríguez-Moldes I. Development of tyrosine hydroxylase-immunoreactive cell populations and fiber pathways in the brain of the dogfish Scyliorhinus canicula: new perspectives on the evolution of the vertebrate catecholaminergic system. J Comp Neurol. 2012 Nov;520(16):3574-603.

Carrera I, Molist P, Anadón R, Rodríguez-Moldes I. Development of the serotoninergic system in the central nervous system of a shark, the lesser spotted dogfish Scyliorhinus canicula. J Comp Neurol. 2008 Dec;511(6):804-31.

Chiba A, Honma Y, Ito S, Homma S. Somatostatin immunoreactivity in the brain of the gummy shark, Mustelus manazo Bleeker, with special regard to the hypothalamo-hypophyseal system. Biomed Res. 1989;10(3):1-12.

Coolen M, Sauka-Spengler T, Nicolle D, Le-Mentec C, Lallemand Y, Da Silva C, et al. Evolution of axis specification mechanisms in jawed vertebrates: insights from a chondrichthyan. PLoS One. 2007 Apr;2(4):e374.

Dryer L, Graziadei PP. Projections of the olfactory bulb in an elasmobranch fish, Sphyrna tiburo: segregation of inputs in the telencephalon. Anat Embryol (Berl). 1994 Dec;190(6):563-72.

Duan D, Fu Y, Paxinos G, Watson C. Spatiotemporal expression patterns of Pax6 in the brain of embryonic, newborn, and adult mice. Brain Struct Funct. 2013 Mar;218(2):353-72.

Fernández AS, Pieau C, Repérant J, Boncinelli E, Wassef M. Expression of the Emx-1 and Dlx1 homeobox genes define three molecularly distinct domains in the telencephalon of mouse, chick, turtle and frog embryos: implications for the evolution of telencephalic subdivisions in amniotes. Development. 1998 Jun;125(11):2099-111.

Ferreiro-Galve S, Candal E, Rodríguez-Moldes I. Dynamic expression of Pax6 in the shark olfactory system: evidence for the presence of Pax6 cells along the olfactory nerve pathway. J Exp Zoolog B Mol Dev Evol. 2012 Mar; 318(2):79-90

Ferreiro-Galve S, Carrera I, Candal E, Villar-Cheda B, Anadón R, Mazan S, et al. The segmental organization of the developing shark brain based on neurochemical markers, with special attention to the prosencephalon. Brain Res Bull. 2008 Mar;75(2-4):236-40.

Fuss T, Schluessel V. Immediate early gene expression related to learning and retention of a visual discrimination task in bamboo sharks (Chiloscyllium griseum). Brain Struct Funct. 2018 Dec;223(9):3975-4003.

Garcia-Calero E, López-González L, Martínezde-la-Torre M, Fan CM, Puelles L. Sim1-expressing cells illuminate the origin and course of migration of the nucleus of the lateral olfactory tract in the mouse amygdala. Brain Struct Funct. 2021 Mar;226(2):519-62.

Garcia-Calero E, Martínez-de-la-Torre M, Puelles L. A radial histogenetic model of the mouse pallial amygdala. Brain Struct Funct. 2020 Sep;225(7):1921-56.

Garcia-Calero E, Puelles L. Development of the mouse anterior amygdalar radial unit marked by Lhx9-expression. Brain Struct Funct. 2021 Mar;226(2):575-600.

Garcia-Calero E, Puelles L. Histogenetic radial models as aids to understanding complex brain structures: the amygdalar radial model as a recent example. Front Neuroanat. 2020 Nov; 14:590011.

García-López M, Abellán A, Legaz I, Rubenstein JL, Puelles L, Medina L. Histogenetic compartments of the mouse centromedial and extended amygdala based on gene expression patterns during development. J Comp Neurol. 2008 Jan;506(1):46-74.

Gerlach G, Wullimann MF. Neural pathways of olfactory kin imprinting and kin recognition in zebrafish. Cell Tissue Res. 2021 Jan; 383(1):273-87.

González A, López JM, Morona R, Moreno N. The organization of the central nervous system of amphibians. In: Kaas J, editor. Evolution of Nervous Systems 2e. Volume 1. Oxford: Elsevier; 2017. pp. 141-70.

González A, Morona R, López JM, Moreno N, Northcutt RG. Lungfishes, like tetrapods, possess a vomeronasal system. Front Neuroanat. 2010 Sep; $4: 130$.

González A, Northcutt RG. An immunohistochemical approach to lungfish telencephalic organization. Brain Behav Evol. 2009;74(1): 43-55.

González A, Northcutt RG. Functional morphology of the brains of sarcopterygian fishes: Lungfishes and Latimeria. In: Farrell AP, editor. Brain and Nervous System, Encyclopedia of Fish Physiology, Academic Press; 2011; p. 46-55.

Hofmann MH, Northcutt RG. Organization of major telencephalic pathways in an elasmobranch, the thornback ray Platyrhinoidis triseriata. Brain Behav Evol. 2008;72(4):307-25.

Holmgren N. Points of view concerning forebrain morphology of lower vertebrates. J Comp Neurol. 1922 Oct;34(5):391-460.

Johnston JB. The telencephalon of selachians. J Comp Neurol. 1911;21(1):1-113.

Joven A, Morona R, González A, Moreno N. Expression patterns of Pax6 and Pax7 in the adult brain of a urodele amphibian, Pleurodeles waltl. J Comp Neurol. 2013a Jun;521(9): 2088-124.

Joven A, Morona R, González A, Moreno N. Spatiotemporal patterns of Pax3, Pax6, and Pax7 expression in the developing brain of a urodele amphibian, Pleurodeles waltl. J Comp Neurol. 2013b Dec;521(17):3913-53.

Joven A, Morona R, Moreno N, González A. Regional distribution of calretinin and calbindin-D28k expression in the brain of the urodele amphibian Pleurodeles waltl during embryonic and larval development. Brain Struct Funct. 2013c Jul;218(4):969-1003. 
Lal P, Tanabe H, Suster ML, Ailani D, Kotani Y, Muto A, et al. Identification of a neuronal population in the telencephalon essential for fear conditioning in zebrafish. BMC Biol. 2018 Apr;16(1):45.

Legaz I, Olmos L, Real MA, Guirado S, Dávila JC, Medina L. Development of neurons and fibers containing calcium binding proteins in the pallial amygdala of mouse, with special emphasis on those of the basolateral amygdalar complex. J Comp Neurol. 2005 Aug;488(4):492-513.

López JM, Moreno N, Morona R, Muñoz M, Domínguez L, González A. Distribution of somatostatin-like immunoreactivity in the brain of the caecilian Dermophis mexicanus (Amphibia: Gymnophiona): comparative aspects in amphibians. J Comp Neurol. 2007 Mar;501(3):413-30.

López JM, Morona R, Moreno N, González A. The organization of the central nervous system of lungfishes: an immunohistochemical approach. In: Kaas J, editor. Evolution of Nervous Systems 2e. Volume 1. Oxford: Elsevier; 2017. pp. 121-39.

López JM, Morona R, Moreno N, Lozano D, Jiménez S, González A. Pax6 expression highlights regional organization in the adult brain of lungfishes, the closest living relatives of land vertebrates. J Comp Neurol. 2020 Jan;528(1): $135-59$.

Marín O, Smeets WJ, González A. Basal ganglia organization in amphibians: chemoarchitecture. J Comp Neurol. 1998 Mar;392(3):285312.

Martínez-García F, Martínez-Marcos A, Lanuza E. The pallial amygdala of amniote vertebrates: evolution of the concept, evolution of the structure. Brain Res Bull. 2002 Feb-Mar 1;57(3-4):463-9.

Martínez-García F, Novejarque A, Lanuza E. Evolution of the amygdala in vertebrates. In: Kaas J, editor. Evolution of Nervous Systems. Volume 2. Oxford: Elsevier; 2006. pp. 255-334.

Maximino C, Lima MG, Oliveira KR, Batista EJ, Herculano AM. "Limbic associative" and "autonomic" amygdala in teleosts: a review of the evidence. J Chem Neuroanat. 2013 Mar;4849:1-13.

Medina L, Abellán A. Development and evolution of the pallium. Semin Cell Dev Biol. 2009 Aug;20(6):698-711.

Medina L, Abellán A, Vicario A, Castro-Robles B, Desfilis E. The amygdala. In: Kaas J, editor. Evolution of Nervous Systems 2e. Volume 1. Oxford: Elsevier; 2017. pp. 427-78.

Medina L, Bupesh M, Abellán A. Contribution of genoarchitecture to understanding forebrain evolution and development, with particular emphasis on the amygdala. Brain Behav Evol. 2011;78(3):216-36.

Medina L, Legaz I, González G, De Castro F, Rubenstein JL, Puelles L. Expression of Dbx1, Neurogenin 2, Semaphorin 5A, Cadherin 8, and Emxl distinguish ventral and lateral pallial histogenetic divisions in the developing mouse claustroamygdaloid complex. J Comp Neurol. 2004 Jul;474(4):504-23.
Moreno N, González A. Hodological characterization of the medial amygdala in anuran amphibians. J Comp Neurol. 2003 Nov;466(3): 389-408.

Moreno N, González A. Localization and connectivity of the lateral amygdala in anuran amphibians. J Comp Neurol. 2004 Nov;479(2): $130-48$.

Moreno N, González A. Central amygdala in anuran amphibians: neurochemical organization and connectivity. J Comp Neurol. 2005 Aug;489(1):69-91.

Moreno N, González A. The common organization of the amygdaloid complex in tetrapods: new concepts based on developmental, hodological and neurochemical data in anuran amphibians. Prog Neurobiol. 2006 Feb;78(2):61-90.

Moreno N, González A. Evolution of the amygdaloid complex in vertebrates, with special reference to the anamnio-amniotic transition. J Anat. 2007a Aug;211(2):151-63.

Moreno N, González A. Regionalization of the telencephalon in urodele amphibians and its bearing on the identification of the amygdaloid complex. Front Neuroanat. 2007b Dec;1:1.

Moreno N, González A. Development of the vomeronasal amygdala in anuran amphibians: hodological, neurochemical, and gene expression characterization. J Comp Neurol. 2007c Aug;503(6):815-31.

Moreno N, González A, Rétaux S. Evidences for tangential migrations in Xenopus telencephalon: developmental patterns and cell tracking experiments. Dev Neurobiol. 2008 Mar; 68(4):504-20.

Moreno N, Joven A, Morona R, Bandín S, López JM, González A. Conserved localization of Pax6 and Pax7 transcripts in the brain of representatives of sarcopterygian vertebrates during development supports homologous brain regionalization. Front Neuroanat. 2014 Aug;8:75.

Moreno N, López JM, Morona R, Lozano D, Jiménez S, González A. Comparative analysis of Nkx2.1 and Islet-1 expression in urodele amphibians and lungfishes highlights the pattern of forebrain organization in early tetrapods. Front Neuroanat. 2018 May;12:42.

Moreno N, Morona R, López JM, Muñoz M, González A. Lateral and medial amygdala of anuran amphibians and their relation to olfactory and vomeronasal information. Brain Res Bull. 2005 Sep;66(4-6):332-6.

Morona R, González A. Calbindin-D28k and calretinin expression in the forebrain of anuran and urodele amphibians: further support for newly identified subdivisions. J Comp Neurol. 2008 Nov;511(2):187-220.

Morona R, López JM, Northcutt RG, González A. Regional chemoarchitecture of the brain of lungfishes based on calbindin D-28K and calretinin immunohistochemistry. J Comp Neurol. 2018 Jun;526(9):1457-97.

Mueller T, Dong Z, Berberoglu MA, Guo S. The dorsal pallium in zebrafish, Danio rerio (Cyprinidae, Teleostei). Brain Res. 2011 Mar; 1381:95-105.
Nieuwenhuys R, Puelles L. Towards a new neuromorphology. Springer International Publishing; 2016

Northcutt RG, González A. A reinterpretation of the cytoarchitectonics of the telencephalon of the comoran coelacanth. Front Neuroanat. 2011 Feb;5:9.

Northcutt RG, Reiner A, Karten HJ. Immunohistochemical study of the telencephalon of the spiny dogfish, Squalus acanthias. J Comp Neurol. 1988 Nov;277(2):250-67.

Northcutt RG. Brain organization in the cartilaginous fishes. In: Hodgson ES, Mathewson RF, editors. Sensory Biology of Sharks, Skates, and Rays. Arlington. Washington (D.C.): Office of Naval Research; 1978. pp. 117-93.

Northcutt RG. Do teleost fishes possess a homo$\log$ of mammalian isocortex? Brain Behav Evol. 2011;78(2):136-8.

Northcutt RG. Telencephalic organization in the spotted African Lungfish, Protopterus dolloi: a new cytological model. Brain Behav Evol. 2009;73(1):59-80.

Pabba M. Evolutionary development of the amygdaloid complex. Front Neuroanat. 2013 Aug; $7: 27$.

Perathoner S, Cordero-Maldonado ML, Crawford AD. Potential of zebrafish as a model for exploring the role of the amygdala in emotional memory and motivational behavior. J Neurosci Res. 2016 Jun;94(6):445-62.

Porter BA, Mueller T. The zebrafish amygdaloid complex - functional ground plan, molecular delineation, and everted topology. Front Neurosci. 2020 Jul;14:608.

Pose-Méndez S, Candal E, Mazan S, RodríguezMoldes I. Morphogenesis of the cerebellum and cerebellum-related structures in the shark Scyliorhinus canicula: insights on the ground pattern of the cerebellar ontogeny. Brain Struct Funct. 2016 Apr;221(3):1691-717.

Pose-Méndez S, Rodríguez-Moldes I, Candal E, Mazan S, Anadón R. A developmental study of the cerebellar nucleus in the catshark, a basal gnathostome. Brain Behav Evol. 2017;89(1): $1-14$.

Puelles L, Alonso A, García-Calero E, Martínezde-la-Torre M. Concentric ring topology of mammalian cortical sectors and relevance for patterning studies. J Comp Neurol. 2019 Jul; 527(10):1731-52.

Puelles L, Kuwana E, Puelles E, Bulfone A, Shimamura K, Keleher J, et al. Pallial and subpallial derivatives in the embryonic chick and mouse telencephalon, traced by the expression of the genes Dlx-2, Emx-1, Nkx-2.1, Pax-6, and Tbr-1. J Comp Neurol. 2000 Aug;424(3):409-38.

Puelles L, Kuwana E, Puelles E, Rubenstein JL. Comparison of the mammalian and avian telencephalon from the perspective of gene expression data. Eur J Morphol. 1999 Apr;37(23):139-50.

Puelles L, Medina L, Borello U, Legaz I, Teissier A, Pierani A, et al. Radial derivatives of the mouse ventral pallium traced with Dbx1LacZ reporters. J Chem Neuroanat. 2016 Sep; 75(Pt A):2-19. 
Puelles L, Rubenstein JL. A new scenario of hypothalamic organization: rationale of new hypotheses introduced in the updated prosomeric model. Front Neuroanat. 2015 Mar; 9:27.

Quintana-Urzainqui I, Rodríguez-Moldes I, Candal E. Developmental, tract-tracing and immunohistochemical study of the peripheral olfactory system in a basal vertebrate: insights on Pax6 neurons migrating along the olfactory nerve. Brain Struct Funct. 2014 Jan; 219(1):85-104.

Quintana-Urzainqui I, Rodríguez-Moldes I, Mazan S, Candal E. Tangential migratory pathways of subpallial origin in the embryonic telencephalon of sharks: evolutionary implications. Brain Struct Funct. 2015 Sep;220(5): 2905-26.

Quintana-Urzainqui I, Sueiro C, Carrera I, Ferreiro-Galve S, Santos-Durán G, Pose-Méndez $S$, et al. Contributions of developmental studies in the dogfish Scyliorhinus canicula to the brain anatomy of elasmobranchs: insights on the basal ganglia. Brain Behav Evol. 2012; 80(2):127-41.

Rodríguez Díaz MA, Candal E, Santos-Durán GN, Adrio F, Rodríguez-Moldes I. Comparative analysis of Met-enkephalin, galanin and GABA immunoreactivity in the developing trout preoptic-hypophyseal system. Gen Comp Endocrinol. 2011 Aug;173(1):148-58.

Rodríguez-Moldes I, Carrera I, Pose-Méndez S, Quintana-Urzainqui I, Candal E, Anadón R, et al. Regionalization of the shark hindbrain: a survey of an ancestral organization. Front Neuroanat. 2011 Mar;5:16.

Rodríguez-Moldes I, Manso MJ, Becerra M, Molist P, Anadón R. Distribution of sub- stance P-like immunoreactivity in the brain of the elasmobranch Scyliorhinus canicula. J Comp Neurol. 1993 Sep;335(2):228-44.

Rodríguez-Moldes I, Santos-Durán GN, PoseMéndez S, Quintana-Urzainqui I, Candal E. The brains of cartilaginous fishes. In: Kaas J, editor. Evolution of Nervous Systems 2e. Volume 1. Oxford: Elsevier; 2017. pp. 77-97.

Rodríguez-Moldes I. A developmental approach to forebrain organization in elasmobranchs: new perspectives on the regionalization of the telencephalon. Brain Behav Evol. 2009;74(1):20-9.

Sánchez-Farías N, Candal E. Doublecortin is widely expressed in the developing and adult retina of sharks. Exp Eye Res. 2015 May; 134:90-100.

Santos-Durán GN, Ferreiro-Galve S, Menuet A, Quintana-Urzainqui I, Mazan S, RodríguezMoldes I, et al. The shark alar hypothalamus: molecular characterization of prosomeric subdivisions and evolutionary trends. Front Neuroanat. 2016 Nov;10:113.

Santos-Durán GN, Menuet A, Lagadec R, Mayeur $\mathrm{H}$, Ferreiro-Galve S, Mazan S, et al. Prosomeric organization of the hypothalamus in an elasmobranch, the catshark Scyliorhinus canicula. Front Neuroanat. 2015 Apr;9:37.

Schluessel V. Who would have thought that 'Jaws' also has brains? Cognitive functions in elasmobranchs. Anim Cogn. 2015 Jan;18(1):1937.

Schnitzlein HN, Hoffman HH, Hamel J, Ferrer NC. Parallelisms in fiber relations and variations in nuclear patterns in the phylogeny of the amygdala. Arch Mex Anat. 1967;26:3-13.

Schwarze S, Bleckmann H, Schluessel V. Avoidance conditioning in bamboo sharks (Chiloscyllium griseum and C. punctatum): behav- ioral and neuroanatomical aspects. J Comp Physiol A Neuroethol Sens Neural Behav Physiol. 2013 Oct;199(10):843-56.

Smeets WJ, Nieuwenhuys R, Roberts BL. The Central Nervous System of Cartilaginous Fishes. Structure and Functional Correlations. New York: Springer Verlag; 1983. https://doi.org/10.1007/978-3-642-68923-9.

Smeets WJ. Cartilaginous fishes. In: Nieuwenhuys R, Donkelaar HJ, Nicholson C, editors. The Central Nervous System of Vertebrates. Berlin: Springer-Verlag; 1998. pp. 551-654.

Smeets WJ. The secondary olfactory connections in two chondrichthians, the shark Scyliorhinus canicula and the ray Raja clavata. J Comp Neurol. 1983 Aug;218(3):334-44.

Sobrido-Cameán D, Tostivint H, Mazan S, Rodicio MC, Rodríguez-Moldes I, Candal E, et al. Differential expression of five prosomatostatin genes in the central nervous system of the catshark Scyliorhinus canicula. Comp Neurol. 2020 Oct;528(14):2333-60.

Swanson LW, Petrovich GD. What is the amygdala? Trends Neurosci. 1998 Aug;21(8):32331.

von Trotha JW, Vernier P, Bally-Cuif L. Emotions and motivated behavior converge on an amygdala-like structure in the zebrafish. Eur J Neurosci. 2014 Nov;40(9):3302-15.

Williams HT. The telencephalon of the newborn dogfish shark, Squalus acanthias. J Hirnforsch. 1973;14(3):261-85.

Yáñez J, Folgueira M, Köhler E, Martínez C, Anadón R. Connections of the terminal nerve and the olfactory system in two galeomorph sharks: an experimental study using a carbocyanine dye. J Comp Neurol. 2011 Nov; 519(16):3202-17. 